\title{
The educational gradient of fertility intentions: a meta-analysis of European studies
}

\section{Maria Rita Testa and Fabian Stephany*}

\begin{abstract}
Unlike achieved fertility, fertility intentions are often positively correlated with education. However, the conditions under which such a positive relationship exists are not yet well known. Using 86 pieces of research covering 13 European countries that were published between 1990 and 2011, we assess in a quantitative manner the temporal and cross-country variation in the relationship between educational attainment and reproductive intentions. Because of the sequential nature of reproductive decisions and the gendered nature of each individual's life course, we look separately at childless women and women with one child, and compare women with men. Our findings show that both first and second birth intentions and educational attainment are positively correlated, but that this relationship which is stronger for men than for women - tends to disappear when the normative value of a two-child family is reached. Structural labour market characteristics explain a good portion of the cross-country variance: the educational slope of first and second birth intentions is steeper in countries with large shares of women in vulnerable employment situations or in part-time employment, and is flatter in countries with gender-equal labour force participation and large shares of women in highly qualified employment.
\end{abstract}

\section{Introduction}

Fertility intentions, or intended family size, represent an important channel through which education affects achieved fertility, or actual family size. However, the relationship between fertility intentions and educational attainment is not

\footnotetext{
* Maria Rita Testa (corresponding author), Vienna Institute of Demography of the Austrian Academy of Sciences and Vienna University of Economics and Business, Welthandelsplatz 2, Level 2, 1020 Vienna, Austria

Email: maria.rita.testa@oeaw.ac.at

Fabian Stephany, Vienna University of Economics and Business, Austria
} 
necessarily the same as the relationship between actual fertility and educational attainment. Empirical evidence indicates that more educated women do not necessarily intend to have fewer children than less educated women; they just end up having fewer children. The postponement of childbearing and the parity-specific distribution of fertility intentions (Sobotka 2009) may help to explain this apparent contradiction.

It appears that in recent decades, women are finding that having a high level of education has become more compatible with fertility. This trend is attributable to the increasing social acceptance of women's employment, the implementation of policies facilitating work and family life, and the increasing involvement of men in childcare tasks. The extent to which this trend is real, and is reflected in the literature on fertility intentions, constitutes the core contribution of this paper. Advancing our knowledge of the reproductive decision-making processes of women with low, medium, and high levels of education is useful for formulating policies aimed at stemming further fertility decline.

A large body of research has examined differences in fertility intentions by educational attainment across countries and over time. The findings of these studies on the sign of the education-intention link have been contradictory. Some scholars have shown that highly educated women are more likely than their less educated counterparts to plan to have a large family (e.g. Heiland et al. 2008; Mills et al. 2008), while others have come to the opposite conclusion (e.g. Musick et al. 2009). Recently, some authors have emphasised the role of contextual factors by suggesting that the relationship between education and fertility - and, presumably, fertility intentions - is positive in countries where the institutional arrangements support the compatibility of work and family life, as well as gender equality in the family and in the labour market (Hobson and Oláh 2006; Matysiak 2011; Neyer 2013). In a recent multi-level analysis, the cross-country and temporal variation in the link between education and birth intentions has been investigated at both the individual and the country level, as well as in a micro-macro integrated framework (Testa 2014). The empirical evidence provided in the micro-macro European context suggests that women of reproductive ages are more prone to plan to invest in both education and family size if they live in an institutional context that facilitates work-life balance; that is, in a country where work career and fertility are not seen as incompatible. Most importantly, this study suggests that both being highly educated and living in a country where a large share of women are college educated are positively associated with women's childbearing intentions.

In order to validate these previous findings, which used a cross-sectional multicountry dataset based on limited national sample sizes, we undertake for the first time a meta-analysis of all published research on the effect of educational attainment on fertility intentions. A meta-analytical approach to the study of fertility intentions is entirely new in the literature. As a systematic review of quantitative results, a meta-analytic study cannot produce genuinely innovative results. However, such a study has a twofold advantage over a single research study: namely, it can provide more general outcomes than any single analysis; and it can generate estimates with 
greater statistical power than the estimates produced by a single empirical study. Moreover, because it has a strong comparative point of view, a meta-analysis is particularly suitable for the purposes of our study.

The paper is organised as follows: first, we outline the theoretical framework of fertility intentions; second, we describe the methodological approach and the analytical steps taken in the computation of the meta-sample; next, we present the results in a purely descriptive manner (forest plots) and in a meta-regression format; finally, we discuss the main findings in light of the previous literature.

\section{Theoretical perspectives}

\subsection{The role of education in fertility and reproductive decision-making theories}

Both economic and cultural theories have argued that the increase in female education has played an important role in fertility decline (Becker 1991; Lesthaeghe and Surkyn 1988). However, studies on the educational gradient of second and higher order births have generated mixed results: in Western, Northern, and Southern European countries, second and third births seem to be positively associated with level of education (Kreyenfeld 2002; Caltabiano Castiglioni and Rosina 2009; Kravdal and Rindfuss 2008); while in Eastern European countries, a negative association between fertility and education tends to prevail (see, for example, Muresan and Hoem (2010)). In most countries, educational enrolment and family formation are seen as incompatible (Blossfeld and Huinink 1991). Prolonged enrolment in education has both a direct effect on the timing of fertility (i.e. a delay in the start of childbearing) and an indirect impact on the quantum of fertility (i.e. a reduction in the time left for the progression to higher order births (Ní Bhrolcháin and Beaujouan 2012). Fertility intentions can tell us the extent to which this double negative effect of education on fertility is intentional, or is instead the outcome of fertility plans that are not realised. The prediction made in the literature on the second demographic transition that ideational change lowers people's fertility intentions by emphasising individuals' self-realisation needs and values (Van de Kaa 2002; Caltabiano et al. 2009; Lesthaeghe 2010; McQuillan et al. 2014) has not come true. Post-materialist attitudes do not seem to be negatively correlated with ideal family size, and a considerable number of studies have found that fertility intentions are indeed higher among highly educated than among less educated women (De Wachter and Neels 2011; Mills et al. 2008; Roukolainen and Notkola 2002); and that these intentions are often closely clustered around the level of two children (Testa 2014).

Theories and empirical findings related to fertility are often mechanistically applied to studies of fertility intentions (Ajzen and Klobas 2013; Philipov 2011). However, almost no scholars would argue that a theory on behaviour is fully 
adequate for explaining the intentions that precede it (Philipov 2011). As the predictors of reproductive behaviour are not necessarily the same as the predictors of birth intentions, distinct theoretical frameworks for fertility intentions and achieved fertility are needed. Ideally, both theoretical approaches should seek to answer the question of whether achieved fertility is the result of prior intentions. Currently, no specific demographic theory of fertility intentions exists. Thus, theories of fertility or theories of decision-making are used as the theoretical framework in studies of reproductive intentions.

One of the most common theoretical frameworks of achieved fertility is the micro-economic theory (Becker 1960 and 1991) that posits that the relationship between education and childbearing is explained by two behavioural mechanisms. On the one hand, the income effect suggests that highly educated women are in a better position than less educated women to cope with the direct costs associated with childbearing; although this effect can be attenuated by higher investments in the quality of children, rather than in having additional children (Becker and Lewis 1973). On the other hand, the favourable labour market opportunities and higher earnings associated with higher education can negatively affect fertility, as they increase the cost of engaging in non-market activities such as childrearing (opportunity costs). The effect of education on fertility depends on the balance between the income effect and the opportunity costs, which can vary substantially across societal and institutional contexts (Blossfeld and Huinink 1991; Adsera 2011). This theoretical approach focuses on the observed births, and does not distinguish between intentions and outcomes. Thus, attempts to apply this theory to the study of intended fertility have led to the assumption that the income effect might be supportive of fertility intentions as well, especially in institutional contexts that facilitate the reconciliation of work and family duties (Testa 2014). In Northern Europe, for example, highly educated women are more likely than less educated women to plan to have a second or a third child (Tesching 2012).

Three main psychological theories are applied to the study of fertility intentions: the theory of planned behaviour (TPB), the theory of traits-intentions-desiresbehaviour (TDIB), and the theory of conjunctural action (TCA). Furthermore, the life course theory offers a framework for studying fertility intentions dynamically over an individual's life course, and for making the link between individuals (microlevel dimension) and contexts (macro-level dimension) (Morgan and Taylor 2006). Here, agency refers to individuals constructing their biographies as self-monitored actors within the particular opportunities and constraints they face.

According to the theory of planned behaviour, intentions are the outcomes of three factors: attitudes towards the behaviour, subjective norms, and perceived behavioural control. Attitudes reflect the internal evaluation of positive or negative outcomes that might follow a certain behaviour (e.g. childbearing). Subjective norms refer to a person's perceptions of how the goal is supported or influenced by the members of his or her close social circle. Perceived behavioural control refers to the person's ability to pursue a certain goal given the available resources (e.g. housing or income). While this theory does not explicitly consider the 
educational dimension, it can be reasonably assumed that there is a negative education-intention correlation through the first two factors of attitudes and norms because childbearing competes with education and employment aspirations; and that there is a positive correlation through perceived behavioural control because compared to the less educated, the highly educated tend to have better housing conditions, higher incomes, more stable partnerships, and more resources to access to assisted reproduction services if needed. The main speculative argument is thus that having a high level of perceived behavioural control might lead highly educated women (and men) to form the intention to have a(n additional) child more frequently than their less educated counterparts. Importantly, according to the TPB, perceived behavioural control influences the intentions, but not the behaviour (i.e. the realisation of intentions); whereas actual behavioural control influences both the formation of intentions and the transition path from intentions to behaviour. Research has shown that the decision to become a parent - i.e. the intention to have a first birth - is driven mainly by attitudes and subjective norms (for which we assume that education has a negative influence); while perceived behavioural control is more relevant for the intention to have a second or a higher order birth (for which we assume that education has a positive influence) (Billari et al. 2009). These findings appear to support the existence of a (more) positive education-intention link at high parities. Most of the previous literature has shown that the major effect of education on childbearing relates to the timing rather than the quantum of fertility. A highly educated woman is unlikely to enter parenthood early in her life course, as doing so would likely lower her career prospects and future income (Lappegård 2002). But once a highly educated woman has a first child, she is likely to have a second because her higher earnings enable her to afford private or subsidized childcare, and because she has little remaining time to complete her childbearing career (Kreyenfeld 2002). A less educated woman, by contrast, faces lower opportunity costs for childbearing, and is thus likely to have her first child early in her life course. However, a less educated woman may find it difficult to have a second or a third child because of her low income (Liefbroer and Corijn 1999).

The other two theories of reproductive decision-making emphasise the negative correlation between educational attainment and fertility intentions. The theory of conjunctural action (TCA) postulates that there is a negative educational gradient of fertility intentions; i.e. that highly educated women place a higher value on career success and leisure than less educated women ${ }^{1}$ (Bachrach and Morgan 2011). Similarly, the TDIB argues that highly educated women and men are more likely than their less educated counterparts to be exposed to life paths and turning point events that compete with childbearing (Miller 2011). The life course theory offers

\footnotetext{
1 The theory of conjunctural action (TCA) is based on social theory, psychology, and the life course framework. It takes into account conscious and unconscious processes leading to behaviour and the effect of the social context on the process. Fertility intentions may result from normative schemas people have regarding the concept of family. Therefore, expressing an intention to have two children may not be a commitment to act accordingly, but rather a result of an unconscious schema.
} 
a dynamic perspective of birth intentions as moving targets (Yeatman et al. 2013). This theory suggests that social cues, such as cues to acquire higher educational qualifications, can lead to revisions of fertility intentions over the life course (Hayford 2009), and that these revisions tend to lower fertility more among highly educated than less educated women and men (Iacovou and Tavares 2011; Gray et al. 2012). However, the link between education and fertility intentions may also turn from negative to positive over the life course when specific birth order intentions come into play. Intentions decline with the birth of each additional child (McQuillan 2014; Liefbroer 2009), but they may decrease less among highly educated women and men who can afford to have a larger family than among less educated women and men who cannot.

\subsection{Research hypotheses}

In this analysis, the relationship between educational attainment and fertility intentions is examined across the three main dimensions of gender, parity, and country. According to the theories outlined above, highly educated individuals are more likely than their less educated counterparts to postpone starting a family (Billari and Philipov 2004; Kohler et al. 2002; Rindfuss et al. 1996), and the effects of this delay are more pronounced for women than for men because the timing of the start of childbearing has more implications for women than for men. Moreover, women with low levels of education are more likely than women with high levels of education to start having children before marrying or securing stable employment (Johnson-Hanks et al. 2011). Finally, because the biological window for childbearing is smaller for women than for men, women tend to be more aware of the normative age deadlines for starting a family. However, men also face childbearing constraints related to the male biological clock (Lambert at 2006) and the threat of "leaving it too late" (Thomson and Lee 2011). Far less is known about the effects of the ticking of the biological clock on the birth intentions of men than of women. Generally, young men say they intend to delay childbearing until well into their late twenties and early thirties. Research has shown that a majority of male university students in Australia plan to have children after age 35 (Thomson and Lee 2011), which is the average age at which men's biological fertility begins to decline (Lambert et al. 2006). On the other hand, educational attainment and fertility, whether achieved or intended, are positively correlated among men (see Martin-Garcia 2008 for achieved fertility; and Heiland et al. 2005 for intended fertility). Consistent with the idea that men need to have the ability to provide for their children, less educated men tend to want a smaller family, and are less likely than their better educated counterparts to report having positive first birth intentions (Lappegård et al. 2011). Since the postponement of (the start of) childbearing translates into delayed but not foregone fertility, there is a positive relationship between education and birth intentions. Hence, we hypothesise that the educational gradient of fertility intentions is positive at the beginning of the reproductive career 
for both women and men, but more so for women (who are more likely to postpone) than for men.

Furthermore, we expect to find that highly educated women and men are more likely than their less educated counterparts to say they intend to have a second child because the former generally have more resources for outsourcing childcare than the latter (income effect). The educational gradient of reproductive intentions tends to be positive because of the income effect, which is expected to be steeper among men than among women because men tend to have higher incomes. As the main provider for the family, a man typically has to be in a stable socioeconomic position before planning to have a second or third child (Lappegård et al. 2011; Lappegård 2012). Unlike highly educated men, highly educated women have to counterbalance the income effect of having children. Because men are less involved than women in childbearing and childrearing, men face lower opportunity costs when starting a family (Berrington 2004). Nevertheless, research has shown that the educationintention relationship can still be positive among highly educated women because combining paid work and family responsibilities may be less stressful for college educated women than for less educated women. We therefore expect to find that the educational gradient of second birth intentions is positive for both men and women, and more so for men than for women.

Finally, educational differences in birth intentions are expected to be smaller if labour force participation rates are similar for men and women, and if the share of highly educated women participating in the labour market is large; as these conditions signal to young women of all education groups that it is possible to have both a career and a family with children (Testa 2014). Hence, our third hypothesis reads as follows: The positive correlation between educational attainment and second birth intentions is weaker in countries where the labour market structure favours full-time and regular employment for women. However, we are not able to determine whether the expected smaller differences are due to the higher intentions of the less educated group or to the lower intentions of the highly educated group.

While we recognize that it would be interesting to move beyond the study of second and third birth intentions to investigate higher order births, we restrict our attention to parities zero, one, and two because of the limitations of the data, which do not contain enough cases to allow us to analyse the decision-making processes at parities higher than two.

\section{Data and Methods}

\subsection{Research design}

Meta-analysis is useful for synthesising and interpreting research results from different studies that cover one specific topic of interest. This method has been increasingly used in the social sciences (Cook and Leviton 1980; Wampler 1982; 
Amato and Keith 1991; Waldforf and Pillsung 2005; Matysiak and Vignoli 2008; Matysiak and Vignoli 2008; Borenstein 2010). Unlike classical reviews of existing literature, this approach provides a clear and systematic way of comparing interstudy results. The first stage of a meta-analysis consists of conducting a literature review and selecting suitable research papers according to criteria of comparability. In a second stage, using a standardised procedure, the coefficients (or alternative parameters or statistic measures) of each study are recalculated to determine the effect sizes, which measure the association between the dependent and the independent variable in a comparable way.

In this meta-analysis, we selected only published research based on regression analysis; thus, beta coefficients and the related standard errors are the main objects of our meta-analytic sample. The education-intentions link is therefore considered net of possible sociodemographic confounders, including age, parity, and marital status; which are the explanatory variables considered in all of the studies included in the meta-sample. The basic unit in the meta-sample is a set of regression coefficients derived from regression models (i.e. study line ${ }^{2}$ ) that does not correspond to a single study; some studies may include several regressions providing multiple study lines.

Demographers first began asking people to report their childbearing intentions in the late 1970s. But because demographic research on fertility intentions was characterised by bivariate statistical analyses in the subsequent two decades (Westoff and Ryder 1977), we have restricted the temporal scope of our metaanalysis primarily to the past two decades, 1990-2011.

\subsection{The meta-sample}

The selection of studies for the meta-sample is a major trade-off in meta-analysis. A meta-analysis should ideally be comprehensive, but not too heterogeneous (Blettner et al. 1999). While scholars try to collect as many studies as possible, the selected pieces of research must satisfy the criteria of comparability. We adopted a three-step selection procedure. First, appropriate studies were identified by a search of Google Scholar and Web of Knowledge (WoK). Since the focus of this study is on the effect of education on fertility intentions, the following keywords and combinations have been utilised: "fertility intention", "fertility desire", and "education"; or "intended fertility" and "education"; or "fertility intention" and "education"; or "human capital" and "fertility intention"; or "intended number of children" and "education"; or "reproductive decision-making" and "education". Second, previously undiscovered references given in the selected papers were included in the literature collection. Only papers written in English, German, French, and Italian have been considered. In a third step, several experts, nine in total, were

2 Each horizontal line put onto a forest plot represents a separate study being analysed, or a study line. 
consulted for recommendations of papers not gathered in the first two phases. After seeking their advice, we were able to identify 161 papers that matched our criteria, of which 84 were found through the web search and 77 were recommended by the experts. Finally, this number was reduced considerably by excluding papers for a variety of reasons: e.g. the lack of a quantitative description of the relationship between education and fertility intentions, inaccurate measurements of education and/or fertility intentions, or a focus on specific sub-groups. After these exclusions were made, 29 papers with a total of 86 study lines remained in the meta-sample (Table 2). This final sample also contains four papers and 11 study lines in which gender has not been distinguished. In 58 of the study lines $(66 \%)$, only women's education was considered; in 19 of the study lines (22\%), both women's and men's education were examined; and in 11 study lines (12\%), both women and men were considered, but there was no stratification by gender. This third group of study lines could not be considered in the forest plot analysis, which is conducted separately for women and men; but it was included in the meta-regression analysis, which includes gender as a control variable. For models that were built using a step-wise procedure (i.e. a gradual inclusion or exclusion of explanatory variables), only the full model specification was considered in the meta-analysis. To avoid study selection bias, results from different studies based on the same dataset have all been included in the analysis. The final meta-analytic sample covers studies conducted in the following 13 European countries: Austria, Bulgaria, Finland, France, Germany, Hungary, Italy, Norway, Poland, Russia, Switzerland, the Netherlands, and the United Kingdom. The selected meta-analytic studies were published between 1990 and 2011, and most (85\%) were published between 2001 and 2011.

\subsection{Fertility intentions measures}

Measuring childbearing intentions is a challenging task because intentions encompass several dimensions. One important distinction is between intentions/plans and ideals/desires: intended fertility may not be the same as ideal fertility given no constraints. Another distinction is made between lifetime intentions (so-called child-number intentions or quantum intentions) and short-term intentions (so-called child-timing intentions or time-dependent intentions), which are parity-specific and depend on the number of children already born. Lifetime intentions refer to the number of children an individual intends to have over his or her whole reproductive life, while short-term intentions refer to a small temporal framework in which the intention to have the first or the next child is confined.

In building the meta-sample, we selected articles using the terms "desire" and "want", as well as the term "intention". It is generally assumed that "want" captures wishes or feelings not directly linked to action, while "intend" captures concrete plans or conscious commitments to act. We did not restrict our analysis to one of these categories for two reasons. First, focusing merely on intentions would have considerably decreased the available meta-sample size. Second, desires have 
been found to be even more predictive of reproductive behaviour than intentions, which suggests that a clear-cut distinction between the two measures might not be perceived by the interviewed individuals asked to report their answers in the survey (Miller 2011). Studies that refer to fertility desires, or ideals, rather than to intentions constitute just $15 \%$ of the whole meta-sample (13 out of 86 study lines) ${ }^{3}$ (Table 1).

The meta-analysis covers studies that refer to all three measures of intentions: i.e. general childbearing intentions (the intention to have a(nother) child); childnumber intentions (the intention to have a given number of children ${ }^{4}$ ), and childtiming intentions (the intention to have a(nother) child in a short-term period, usually the next two or three years). We decided we would not restrict our focus to just one of these measures because of the limited number of available papers in each of these categories. Of the study lines in the final meta-sample, $73 \%$ refer to general childbearing intentions, $20 \%$ to child-timing intentions, and only $7 \%$ to child-number intentions. The intention to have a first or another child, irrespective of timing and quantum, captures the intended parity transitions if information on the number of children already born is available and is controlled for in regression modelling; in such a case, the general intention to have another child becomes the specific first, second, third, or higher order birth intention. In most of the study lines in the meta-sample, a control for the number of children already born has been included. A summary of the different expressions of fertility intentions used in the studies covered by the meta-analysis is reported in Table 1 .

\subsection{The analytical approach}

A crucial step in the meta-analysis is the computation of the effect sizes. In our case, the effect size is the difference between the effect of being highly educated and the effect of being less educated on fertility intentions. The following formula has been used for computation:

$$
\mathrm{ES}=\left\{\begin{array}{l}
\mathrm{COEF}_{\text {high }}-\mathrm{COEF}_{\text {low }}, \\
\left.\log \left(\mathrm{COEF}_{\text {high }}\right)-\log \left(\mathrm{COEF}_{\text {low }}\right), \quad \text { for Exp. models (e.g., Odds ratios }\right),
\end{array}\right.
$$

where ES stands for effect size, COEF stands for coefficient, and the subscripts "high" and "low" refer to the educational attainment categories; i.e. the highest and the lowest educational level, respectively. In the case of exponential models, the log-transformation of the coefficients has been used to compute the differences between the low and the high education category. Effect sizes are used to compare

\footnotetext{
3 Robustness checks showed that the results from the studies that used intentions only did not differ significantly from the results based on the larger meta-sample that also included desires and ideals.

4 Research studies using the variable "intention to have a given number of children" were included in the meta-analysis only if the contrast between zero children and one child or more (the choice between a family with or without children) was modelled in the regression analysis.
} 


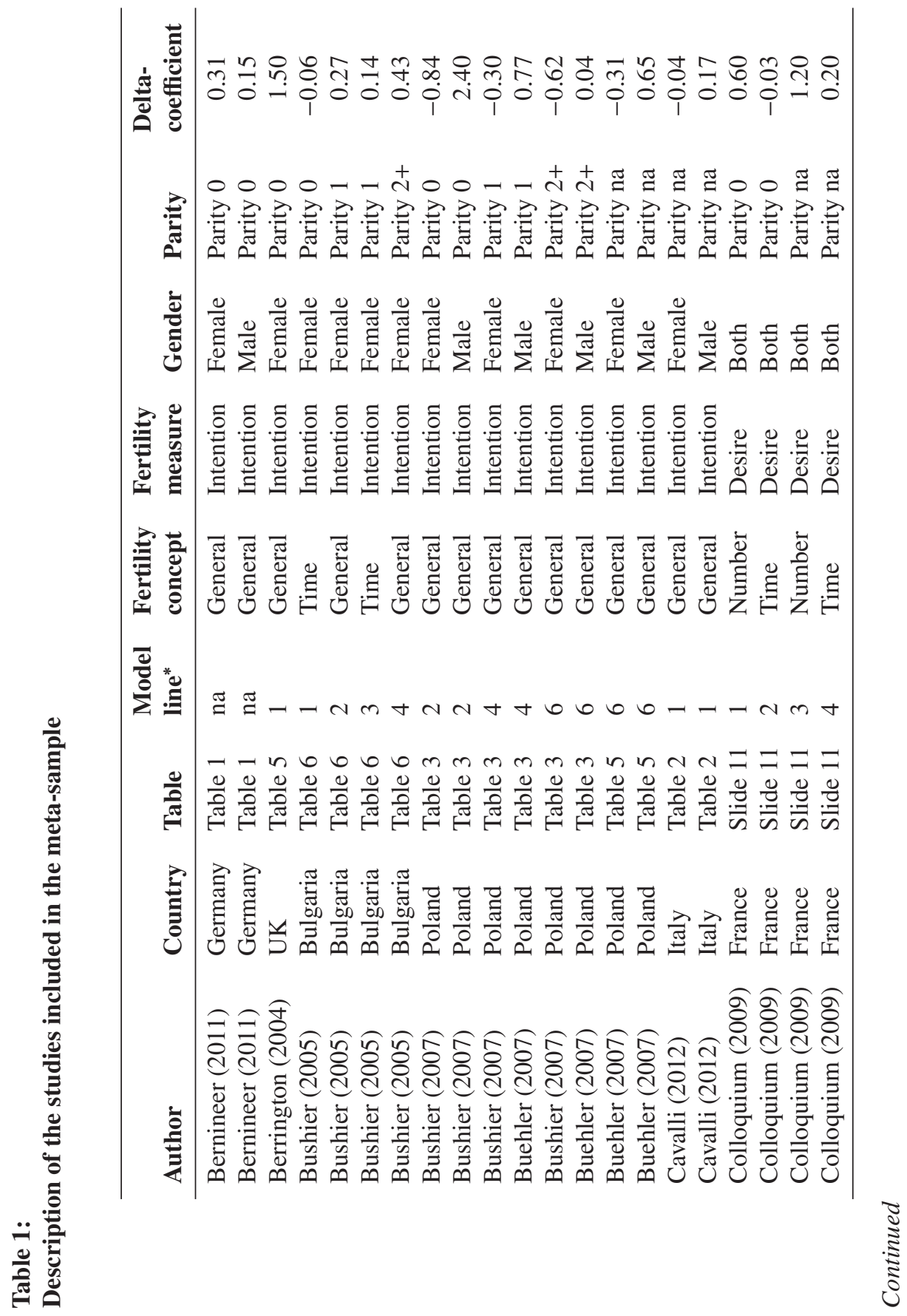




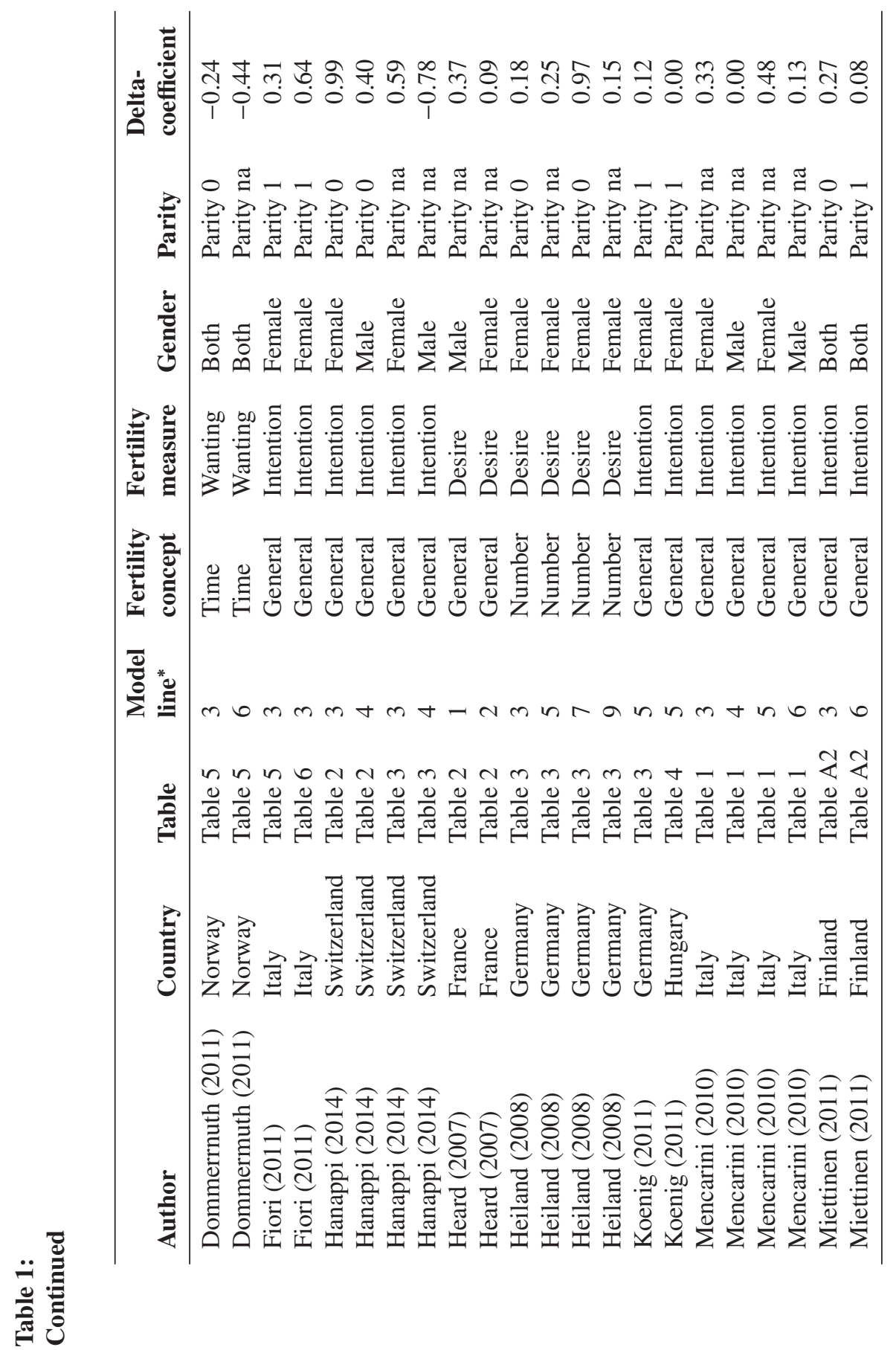

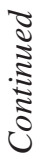




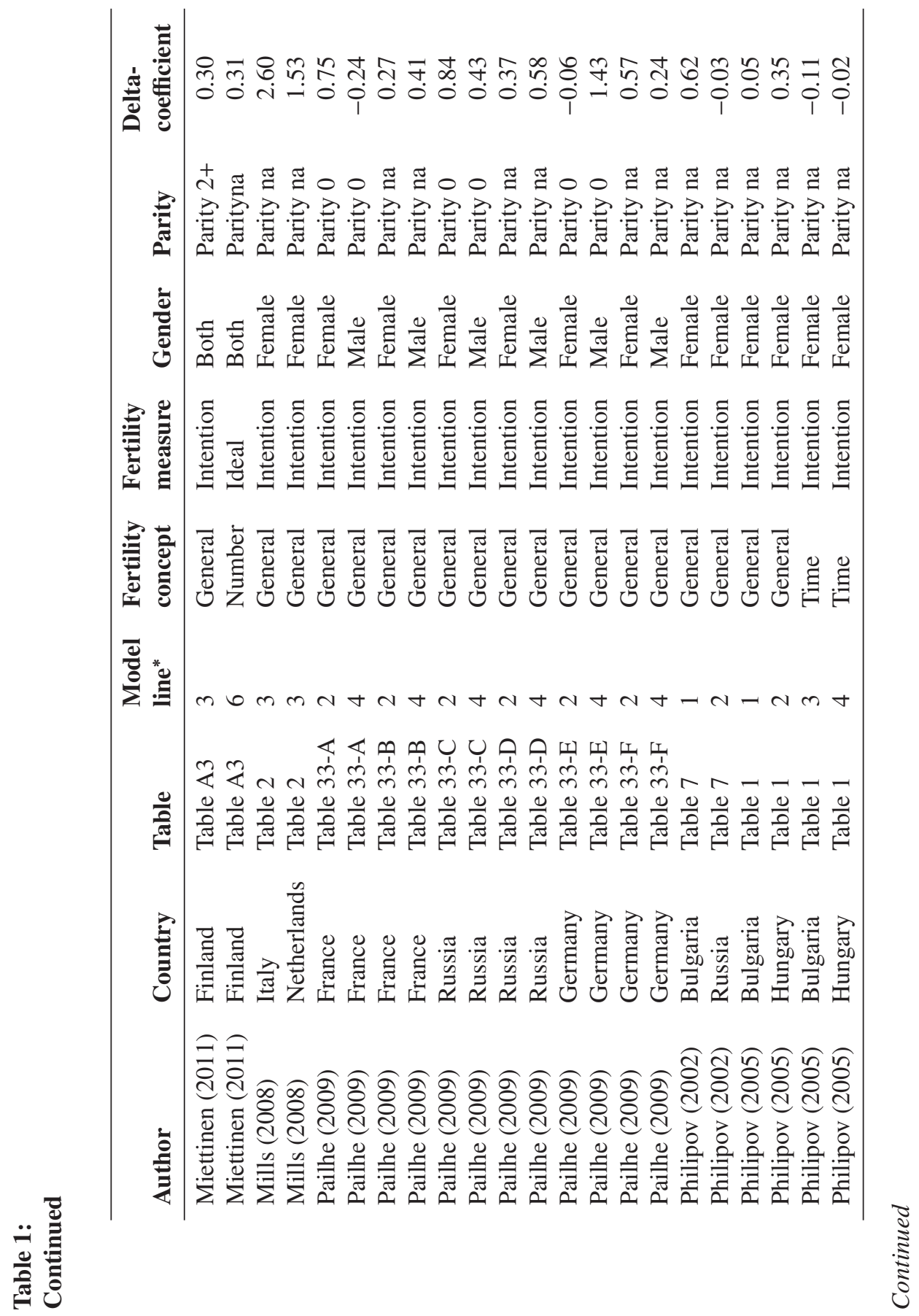




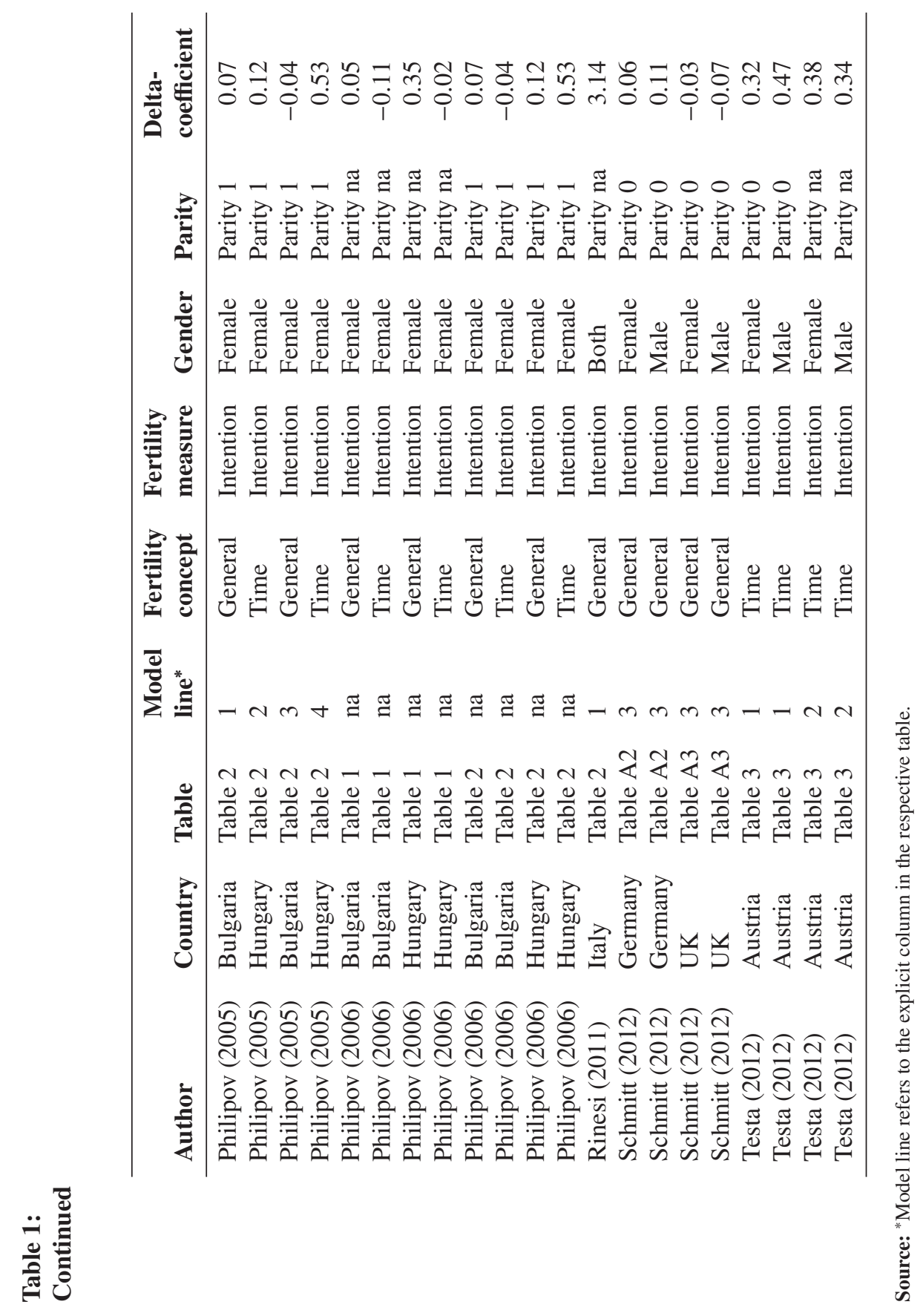


the educational gradients of women's and men's fertility intentions across parities, and to serve as an outcome variable in the regression models aimed at explaining the variation in the educational gradient across individuals' socio-demographic characteristics and countries. The effect sizes are also the outcome variables in the meta-regressions that use random effects. The random approach postulates that the ESs vary from study to study according to the underlying sample, and that a theoretically infinite number of study-specific ESs would then be distributed around some mean. The ES in the performed studies has to be interpreted as just a (random) sample of a particular given distribution of ESs (Borenstein et al. 2010). A main advantage of considering random effects is that the ES variance can be decomposed into two parts: a between-study variance that refers to the differences across studies, and a within-study variance that refers to the differences across models in the same study. The regression equation of the random effects model can be formalised as follows:

$$
y_{i}=\alpha+\theta+\beta x_{i}+\varepsilon_{i}+\mu_{i}, \quad \varepsilon_{i} \sim N\left(0, \sigma_{i}^{2}\right), \mu_{i} \sim N\left(0, \tau^{2}\right)
$$

The model assumes two different types of effect sizes, a within and an across study effect size:

$$
\begin{array}{rr}
y_{i}=\theta_{i}+\varepsilon_{i}, & \varepsilon_{i} \sim N\left(0, \sigma_{i}^{2}\right) \\
\theta_{i}=\theta+\beta x_{i}+\mu_{i}, & \mu_{i} \sim N\left(0, \tau^{2}\right)
\end{array}
$$

Here, $y_{i}$ is the estimated effect size in study $i$ and $\theta_{i}$ is the true effect in this study. $\theta$, on the other hand, is the overall true effect. The disturbance of the estimation of $y_{i} \varepsilon_{i}$, is assumed to be standard normal distributed. $\sigma_{i}^{2}$ in (3) is the within-study variance, and $\tau^{2}$ in (4) is the variance across studies.

In the computation of the effect sizes, several challenges had to be faced. First, we had to re-compute (or standardise) the different educational level categories. In most of the studies, education had been coded as a three-categorical variable of "low", "medium", and "high"; with "low" corresponding to compulsory primary education and "high" corresponding to completed university education. This categorisation was kept as a benchmark for all studies, which had some important implications. In cases in which the open category "secondary education and above" was used for the highest educational attainment, this category was defined as "high", while all categories below the complete high school were marked as "low". Studies in which education was coded in a binary fashion could not be considered and were not included in the meta-sample. If education was treated as a continuous variable, the coefficient, or its logarithm, was multiplied by the number of years needed to complete tertiary education in order to obtain a comparable effect size. Another major challenge concerned the estimation of the standard errors in cases in which the intermediate category "medium level of education" had not served as a reference group (for more on this issue, see Matysiak et al. 2014). The aggregation of two single standard errors is usually a difficult task, and it is even harder if only pvalues are given; in such cases, the results of recalculations become more imprecise. A common and direct approximation criterion for the standard error of the effect 
size uses the inverse of the study's sample size. The underlying assumption here is that studies with larger sample sizes tend to have more precise estimates. Since the sample sizes vary greatly across our meta-sample, the inverse of the logarithmic sample size has been used.

For the sake of simplicity, the countries were grouped into four clusters in the meta-regression analysis: Northern European countries, Central European countries, Southern European countries, and Eastern European countries (Table 2). ${ }^{5}$ The clusters correspond to different family regimes and levels of women's labour force participation (Engelhardt et al. 2004), and largely reflect a grouping adopted by several other scholars investigating fertility levels in Europe (Frejka and Sardon 2004; Goldstein et al. 2009; Wilson 2013); with the exception of the UK, which is considered together with the Northern European countries. Northern European countries support the dual-earner family and the combining of work and family (Thévenon 2008), and are characterised by favourable attitudes towards working mothers (Korpi 2000) and high levels of commitment to gender equality (Duvander et al. 2010). Western European countries are characterised by attitudes that view women as supplementary income providers, and that emphasise women's roles as care-takers. Thus, these countries tend to follow a male breadwinner model and a female part-time career model (Baranowska-Rataj and Matysiak 2014). The Southern European countries also tend to follow the male breadwinner model, and are characterised by a labour market that does not favour women's participation (Esping-Andersen 1999). Finally, the Eastern European countries are characterised by gender equality in the labour market (with high shares of women participating in the labour force and in full-time employment), and by an unequal gender division of childrearing and household tasks; this combination puts a so-called "double burden" on women (Kocourková 2002). In the meta-sample, the structure of the clusters is unbalanced, with Central Europe being the most represented area (38\% of all study lines), and Southern and Northern Europe being the least represented areas (17\% of all study lines each) (Table 2). The effect sizes were tested for homogeneity (Hedges and Olkin (1985), and the results confirmed that there is a large degree of variation in the estimated effect sizes. The source of this variation might be related to the different social, economic, and institutional contexts of fertility intentions (especially the labour market and gender system); and to differences in the way education was measured (whether continuously or discretely). The meta-regression was carried out in order to test for the influences of country- and study-specific characteristics on the effect sizes. The software Stata/SE version 13.1 was used (see Sterne 2009); more precisely, the command "metan" was employed for the forest plot analysis and the command "metareg" was employed for the meta-regression analysis.

\footnotetext{
5 Northern Europe refers to Finland, Norway, and the United Kingdom. Central Europe refers to France, the Netherlands, and the German-speaking region (Austria, Germany, and Switzerland). Southern Europe refers to Italy. Eastern Europe refers to Hungary, Poland, Bulgaria, and Russia.
} 
Table 2:

Description of the meta-sample by country and country cluster

\begin{tabular}{|c|c|c|c|c|c|}
\hline \multirow[b]{2}{*}{ Regions } & \multirow[b]{2}{*}{ Countries } & \multicolumn{2}{|c|}{ Papers* } & \multicolumn{2}{|c|}{ Study lines } \\
\hline & & $N$ & $\%$ & $N$ & $\%$ \\
\hline \multicolumn{6}{|c|}{ Southern Europe } \\
\hline & Italy & 5 & $18 \%$ & 10 & $12 \%$ \\
\hline & Total & 5 & $18 \%$ & 10 & $12 \%$ \\
\hline
\end{tabular}

Northern Europe

$\begin{array}{lrrrr}\text { Finland } & 1 & 4 \% & 4 & 5 \% \\ \text { Norway } & 1 & 4 \% & 2 & 2 \% \\ \text { UK } & 2 & 7 \% & 3 & 3 \% \\ \text { Total } & \mathbf{4} & \mathbf{1 4 \%} & \mathbf{9} & \mathbf{1 0 \%}\end{array}$

Central Europe

$\begin{array}{lrrrr}\text { Austria } & 1 & 4 \% & 4 & 5 \% \\ \text { France } & 3 & 11 \% & 10 & 12 \% \\ \text { Germany } & 5 & 18 \% & 13 & 15 \% \\ \text { Netherlands } & 1 & 4 \% & 1 & 1 \% \\ \text { Switzerland } & 1 & 4 \% & 4 & 5 \% \\ \text { Total } & \mathbf{1 1} & \mathbf{3 9 \%} & \mathbf{3 2} & \mathbf{3 7 \%}\end{array}$

Eastern Europe

$\begin{array}{lrrrr}\text { Bulgaria } & 3 & 11 \% & 13 & 15 \% \\ \text { Hungary } & 2 & 7 \% & 9 & 10 \% \\ \text { Poland } & 1 & 4 \% & 8 & 9 \% \\ \text { Russia } & 2 & 7 \% & 5 & 6 \% \\ \text { Total } & \mathbf{8} & \mathbf{2 9 \%} & \mathbf{3 5} & \mathbf{4 1 \%} \\ & & & & \\ \mathbf{1 3} & \mathbf{2 8} & \mathbf{1 0 0 \%} & \mathbf{8 6} & \mathbf{1 0 0 \%}\end{array}$

Source: *In five papers two countries are covered, one paper contains three countries.

Note: The number of study lines included in the table does not match the number of study lines displayed in the forest plots of Figures 1 and 2, because in Figures 1 and 2 studies using the measures "wanting", "desire", or "ideal" have not been included.

\subsection{The meta-regression}

The outcome variable of the meta-regression is the effect size; i.e. the educational gradient of fertility intentions as described in formula (4). The $\theta_{i}$ in formula (4) can be obtained as follows:

$$
\theta_{i}=\theta+\beta X+\mu_{i}, \text { while } \mu_{i} \sim N\left(0, \tau^{2}\right),
$$

where $X$ represents the set of regressors, or explanatory variables, and $\beta$ is the set of coefficients. 
The explanatory variables include: (1) a dummy indicating whether the study used "number", "timing", or "general" intentions; (2) a dummy indicating whether the study used the term "intention" or "desires"; (3) the midpoint of the calendar interval in which the study was carried out; (4) a dummy indicating whether the study contained results for women only; (5) one dummy for parity one and one dummy for parity two and above; and (6) one dummy for each group/cluster of countries. In addition, in order to test hypothesis three, four macro-level indicators have been included in the regression: (1) the share of total female employment that was part-time; (2) the percentage of women with tertiary education among all women participating in the labour force; (3) the ratio of the female to the male labour force participation rate; and (4) the percentage of total female employment that was temporary. ${ }^{6}$ The selection of these variables was inspired by a previous study (Bellani and Esping-Andersen 2013), which suggested that family-friendly labour market policies positively influence the intentions of second and higher order births, especially of highly educated women. These labour market features have an impact not just on work-life balance, but on the likelihood that individuals will realise their fertility intentions (Castro-Martín and Martín-García 2013). Moreover, “... these variables are key to identifying the extent to which labour market regulation may help reduce (or increase) the potential opportunity cost of a new birth" (Bellani and Esping-Andersen 2013, p. 92). Since the starting point of the survey periods covered in the meta-sample is the year 1990, all four macro indicators refer to this year. ${ }^{7}$ In addition, a trend component - the percentage change registered between 1990 and 2012, the time period covered in the meta-analysis - has been inserted into the model. We checked the robustness of the meta-regression results by running different sensitivity tests. First, the country with the largest number of studies, Germany, was dropped from the sample. Second, an additional dummy variable indicating whether the educational measure had been adjusted or recalculated was added to the models. Finally, the reference group was switched to Northern Europe. None of the sensitivity tests altered the results reported in Table 3.

\footnotetext{
6 Other macro-economic characteristics were tried, including the following: the percentage of women in the public sector labour force, the share of women in temporary employment, the GDP per capita, the national investments in pre-primary childcare as a percentage of total investments, the UNDP gender inequality index, as well as the 1990-2011 trend components of these measures. None of these indicators were associated with any statistically significant results.

7 If data from 1990 were missing, the earliest data point available was used; see Table 1 for details.
} 


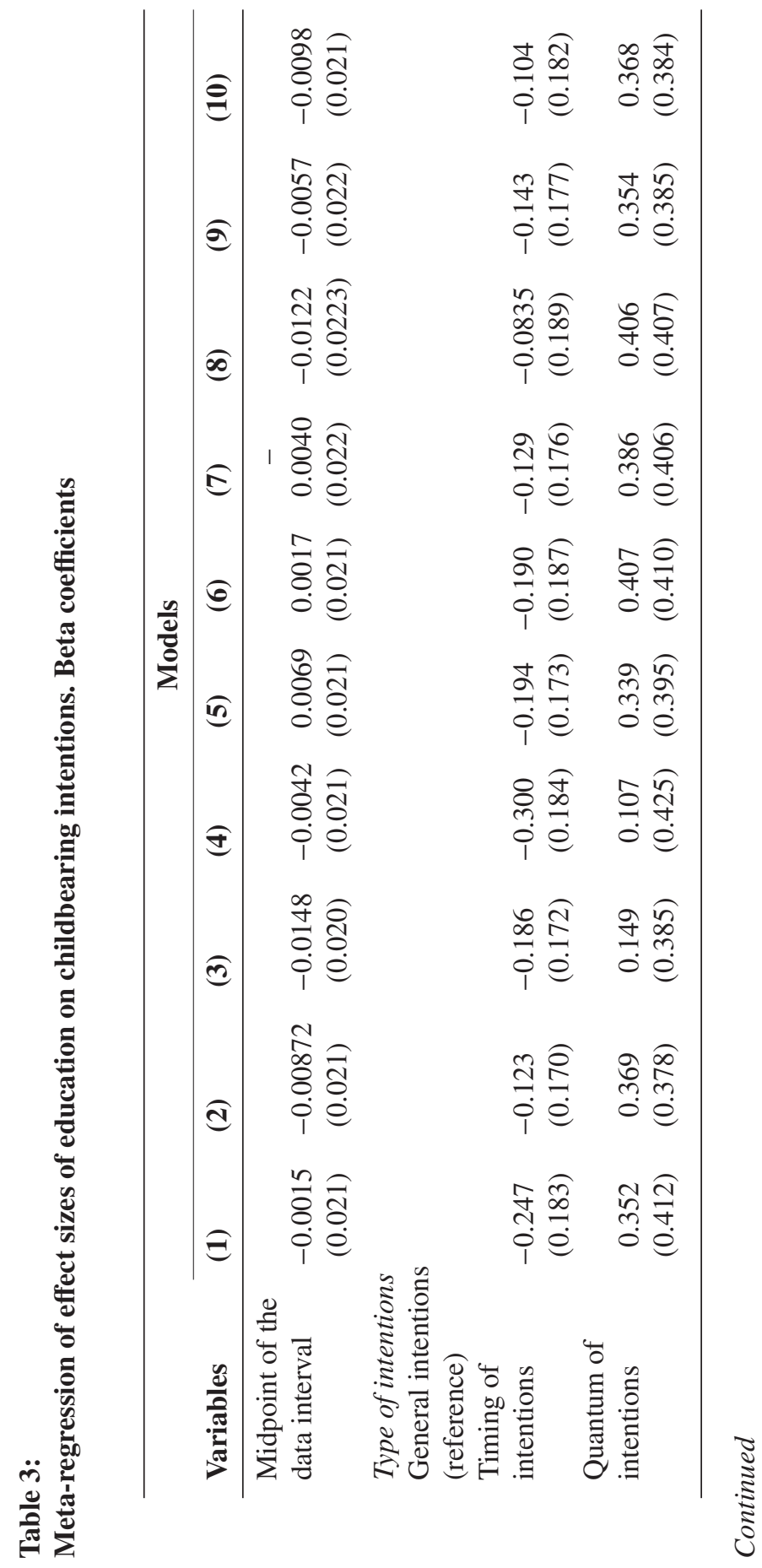




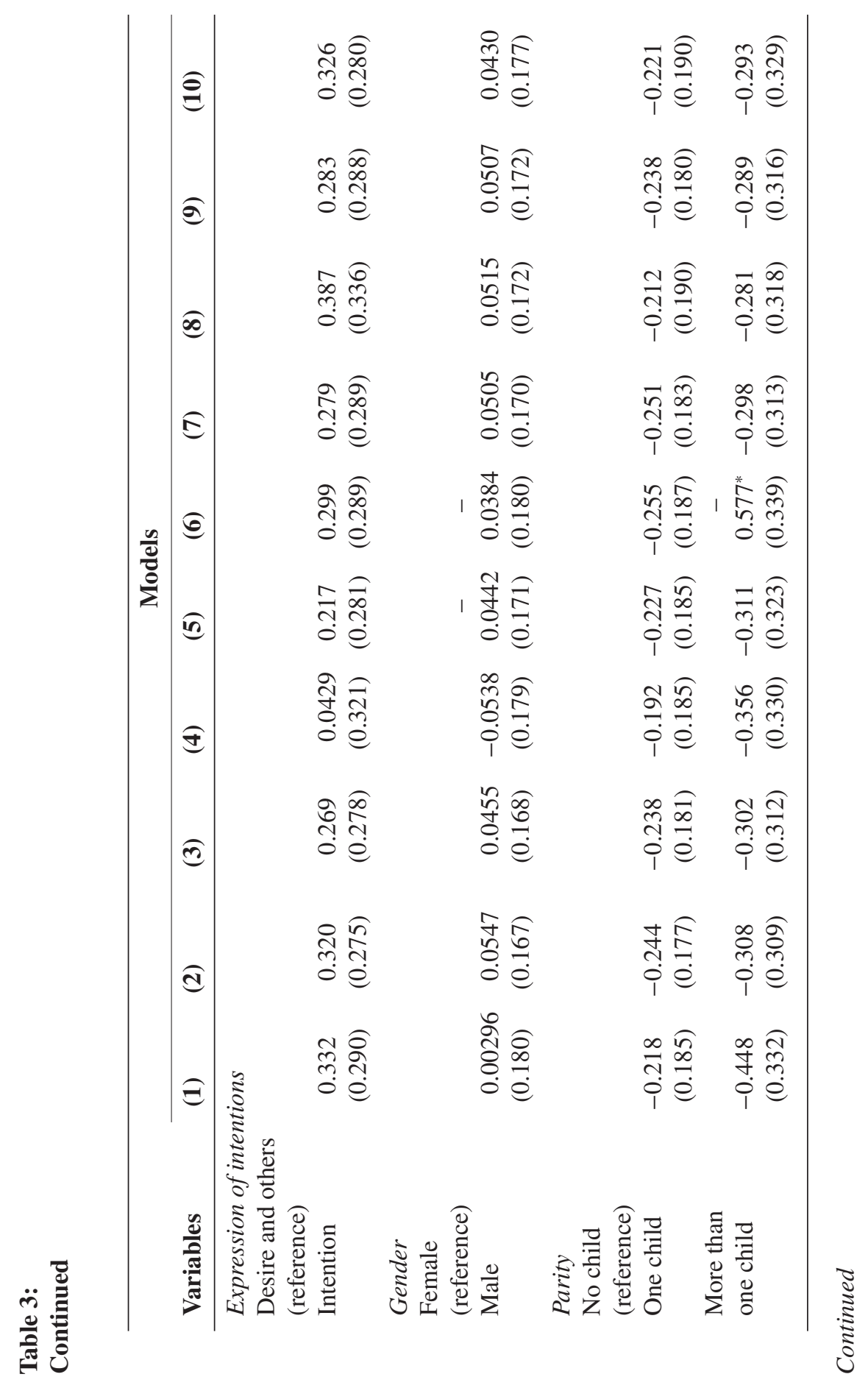




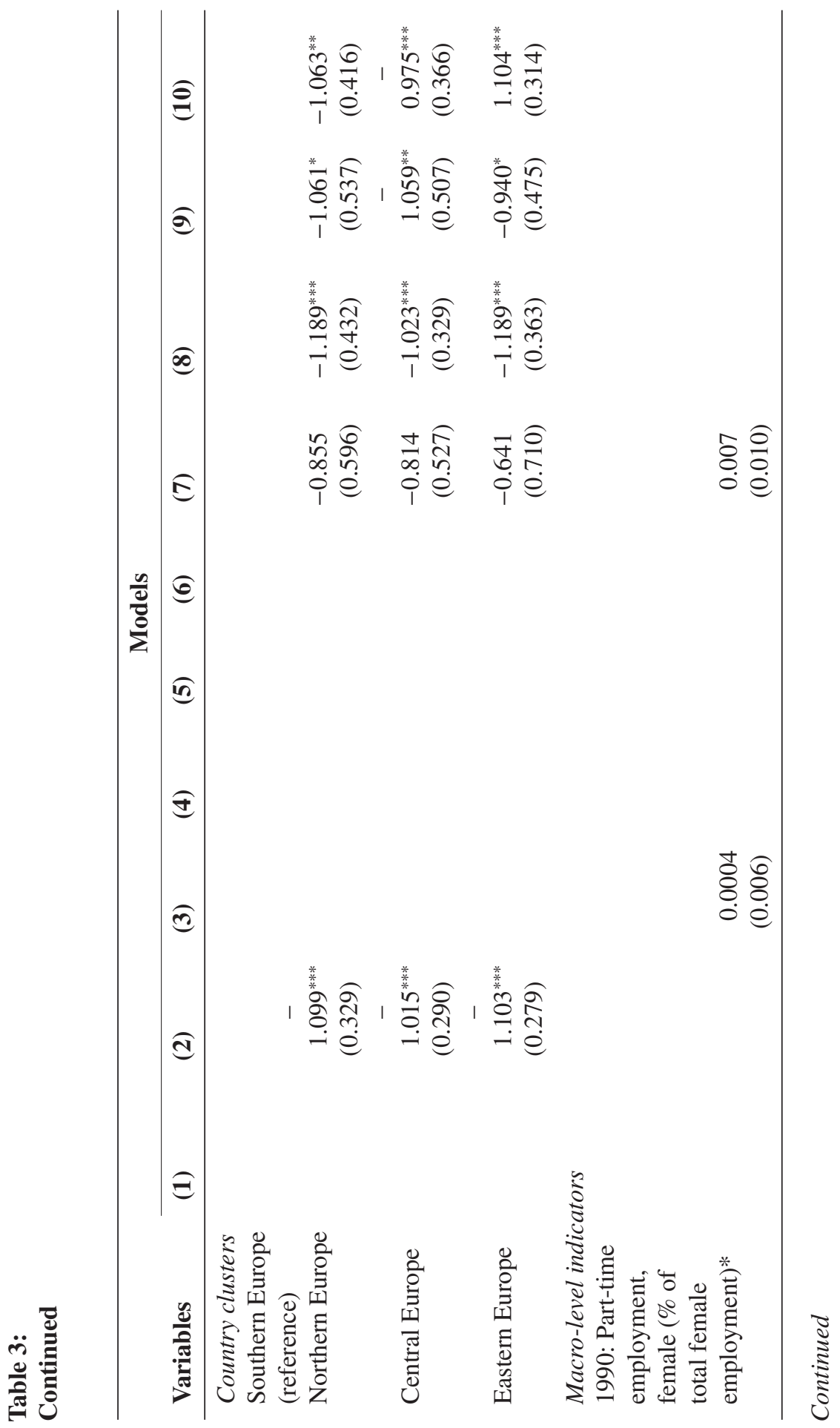




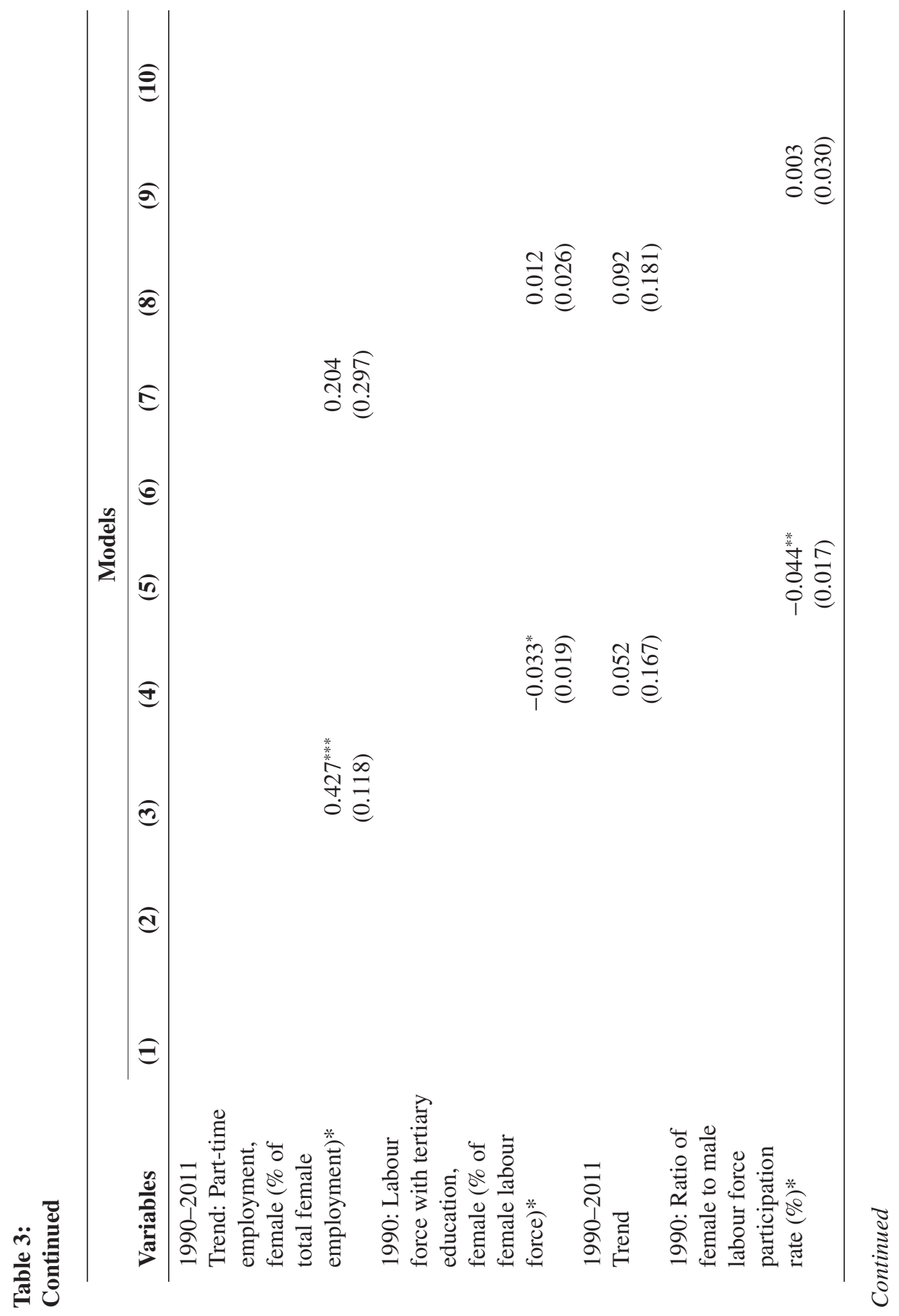




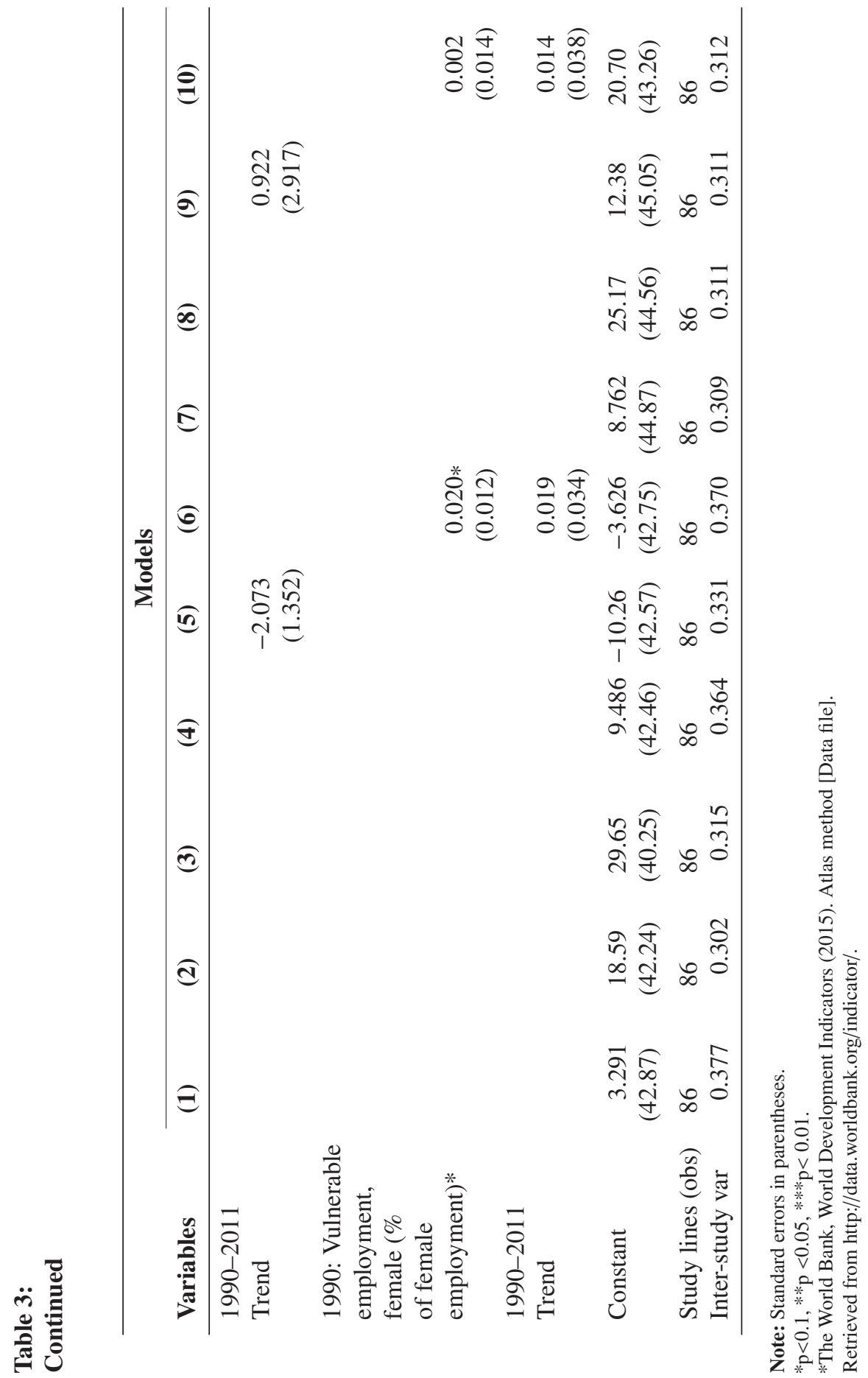


Figure 1 Panel (a):

Effect size of education on childbearing intentions by parity. Women of main reproductive ages

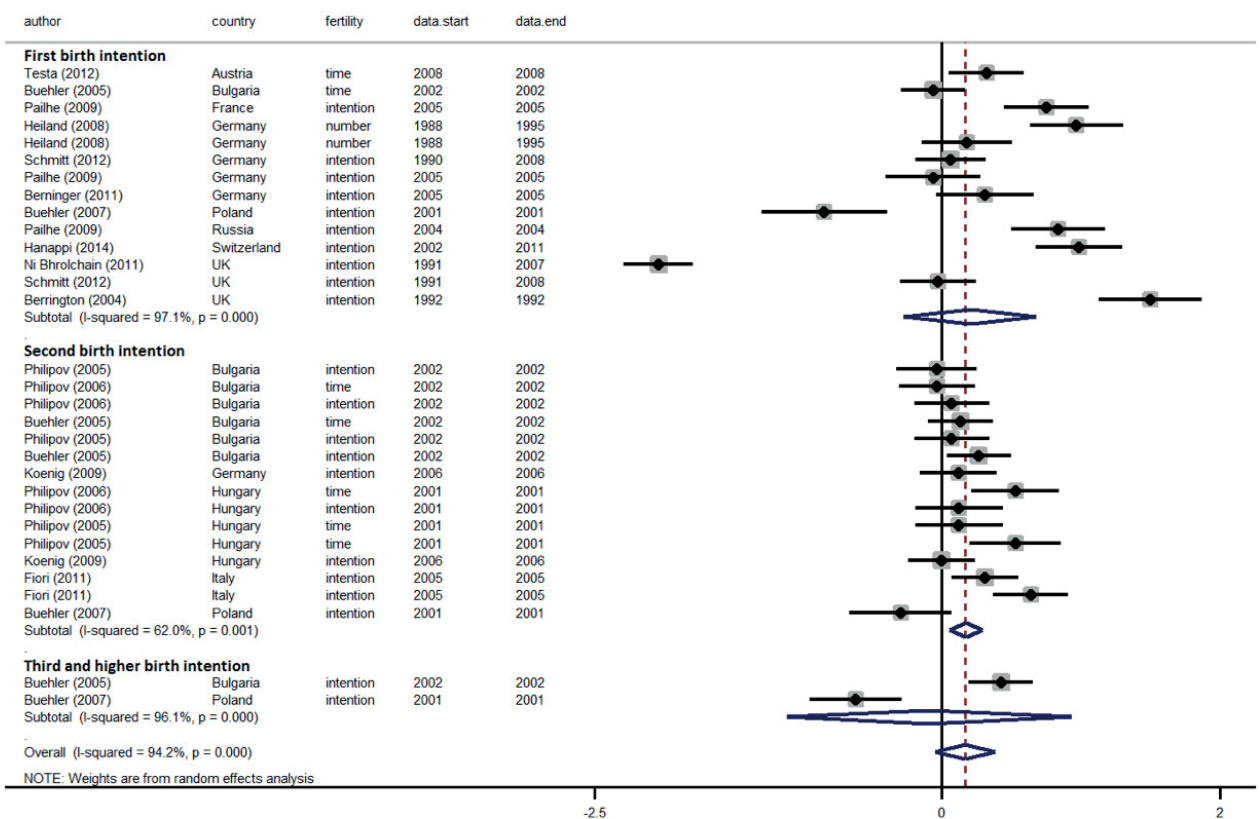

\section{Results}

\subsection{Meta-analytic evidence based on forest plots}

The educational gradient of birth intentions is measured by the effect sizes; i.e. the black dots in the forest plots of Figures 1 and 2 refer to women and men, respectively. The variability of each study's effect size, measured by the $95 \%$ confidence interval, is represented by the black line that crosses the dots horizontally. The average effect sizes by group/parity are displayed by the large diamond that appears at the bottom of each parity group; and the overall average effect size across all parities is given by the diamond at the very bottom of the graph that is centred on the broken vertical line. The unbroken vertical line indicates the null value. Positive effect sizes stand for cases in which highly educated individuals have higher intentions than their less educated counterparts. This interpretation requires some caution, because an increase in the effect sizes could refer to the lower fertility intentions of less educated individuals or the higher fertility intentions of highly educated individuals, or a combination of both. Conversely, a decrease in the effect sizes could result from the higher intentions of less educated individuals or the lower intentions of highly educated individuals, or a combination of both. 
Figure 1 Panel (b):

Effect size of education on childbearing intentions. Women of main reproductive ages at any parity status

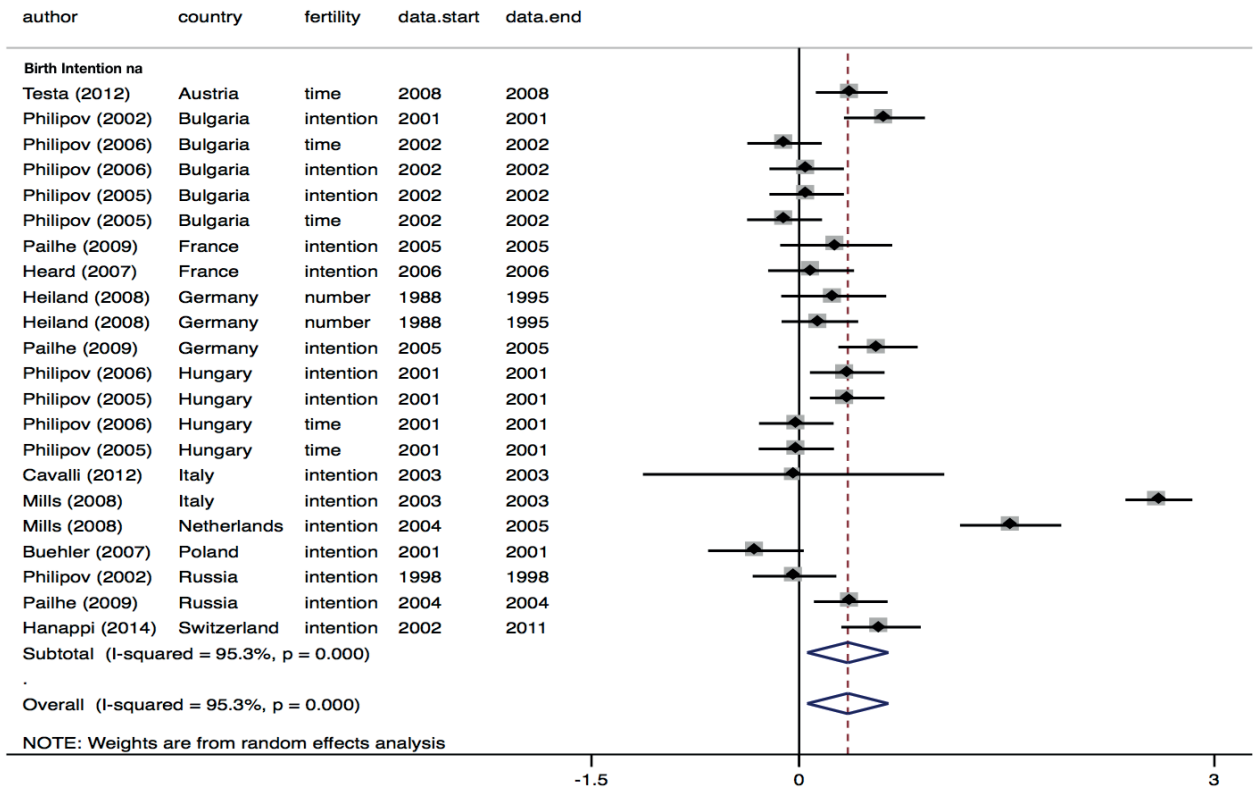

To test hypotheses one and two, we compare the effect size of women and men by parity. The educational gradient of first and second birth intentions is positive in most of the studies for both women and men (Figures 1 and 2). Gender differences tend to become smaller at higher parities. The effect sizes of education on first birth intentions are almost always positive among men, and tend to be positive among women (Figure 2 and Figure 1, respectively; panel (a)). Poland and the United Kingdom provide study lines with negative effect sizes for women (studies by Bühler and Fratczak 2007 and Ní Bhrolcháin and Beaujouan 2011, respectively); this means that in such studies, the first birth intentions of less educated women are higher than those of highly educated women. By contrast, the effect sizes of women's first birth intentions are positive and statistically significant in the following countries: Austria, France, Germany, Russia, and Switzerland (Figure 1, panel (a)).

The black dots of second birth intentions are located mostly in the positive spectrum. As the positioning of the two diamonds at the bottom of the parity groups indicate (Figure 1, panel (a)), the effect size of education on second birth intentions is clearly positive, and is even larger than the effect on first birth intentions. Finally, as the positioning of the diamond at the bottom of the related parity group (Figure 1, panel (a)) shows, the educational gradient of higher birth order 
Figure 2 Panel (a):

Effect size of education on childbearing intentions by parity. Men of main reproductive ages

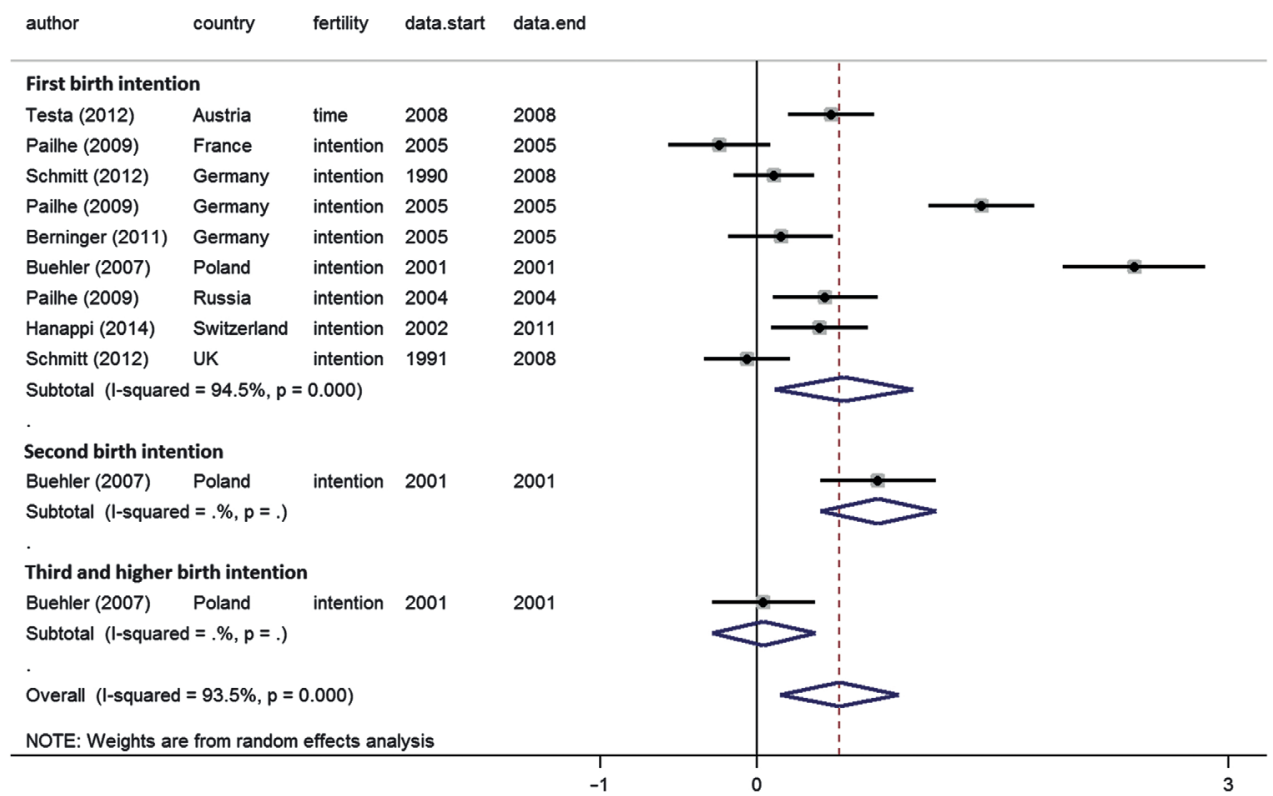

intentions is still positive, but is not statistically significant. To sum up, the positive education-intention relationship is driven mainly by women who have just one child. The relationship is positive at parity zero and parity one, but is statistically significant for second birth intentions only.

Among men, there is no study line for which there is a significant negative effect size of education on first birth intentions: among all of these nine study lines, five show clearly positive effect sizes (Figure 2, panel (a)). The picture does not change substantially for higher birth order intentions. Thus, the overall effect size of education on childbearing intentions is clearly positive and statistically significant (Figure 2, panel (a)).

The variation in the effect of education across parities is greater among women than among men. Overall, there are only a few exceptions to the positive educationintentions relationship: namely, two study lines at parity zero and one study line each at parity two and parity three among women, and two study lines at parity zero among men.

The meta-analytic results that refer to study lines without parity stratification provide further evidence of a generally positive educational gradient in fertility intentions for both men and women (Figures 1 and 2 panel (b)). To sum up, the evidence based on the forest plots suggests that the positive effect of educational 
Figure 2 Panel (b):

Effect size of education on childbearing intentions. Men of main reproductive ages at any parity status

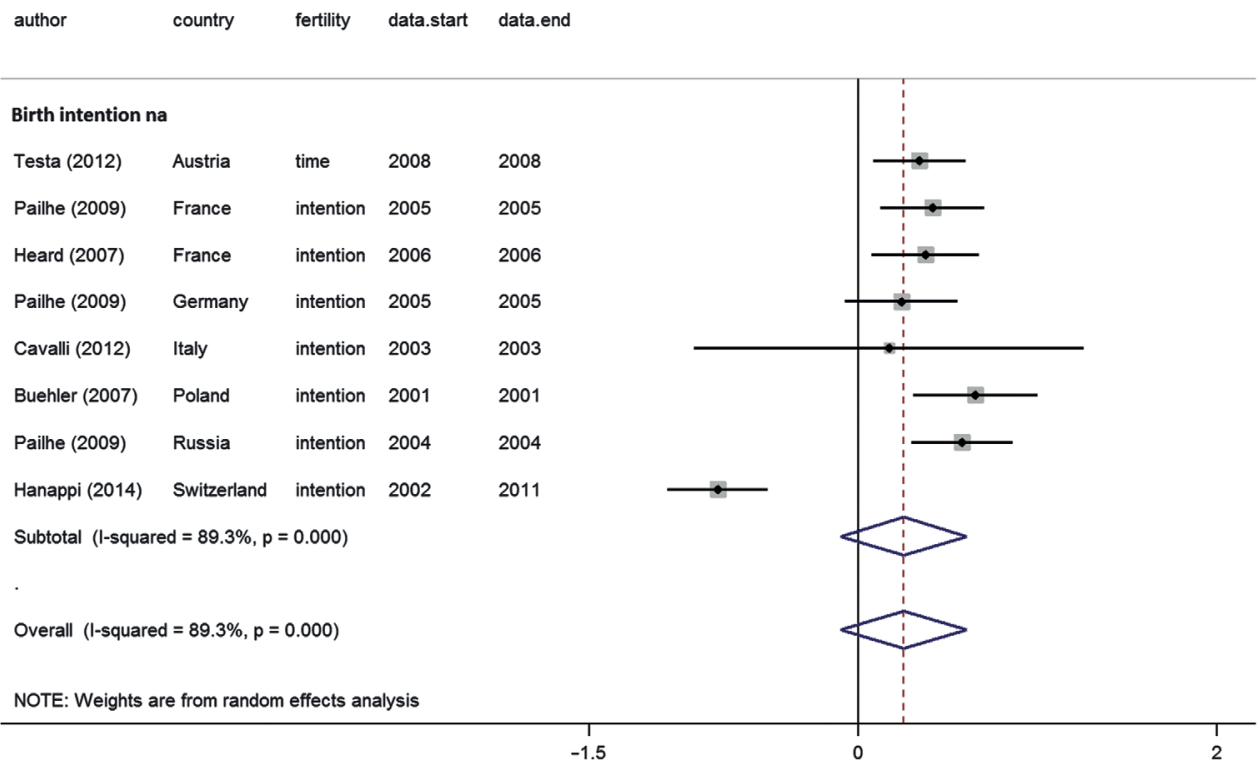

attainment on birth intentions is larger among men than among women; and that among women, it is bigger for second birth intentions than for first birth intentions.

\subsection{Meta-analytic evidence based on regression findings}

In order to account for the cross-regional differences in the educational gradient of birth intentions, we regressed the effect sizes on a set of country clusters dummies (model 2, Table 3); then separately on a set of macro-level indicators (models 3 to 6, Table 3); and, finally, on both sets of covariates at a time (models 7 to 10 , Table 3). In model 1, we included several control variables in the following order: the midpoint of the time covered by the study, two dummies indicating the type of intention (i.e. general childbearing intentions, the timing of births, or the number of children), one dummy indicating whether "intentions" or "desires" were used in the study, one dummy for gender, and two dummies denoting the actual parity status (i.e. one child or two or more children). These explanatory variables were kept in all models (1 to 10). We set Southern Europe (only Italy is available in this group) as a reference category. The educational gradient of fertility intentions is lower in all clusters of countries than it is in Italy (model 2). By combining this finding with the results from the forest plots, it becomes clear that the most relevant geographical 
divide in the educational gradient of fertility intentions is between Southern and Northern Europe, which, respectively, have the largest and the smallest educational gradient of birth intentions. To account for cross-regional differences and to test the third hypothesis, we included in the regression models four macro-level labour market indicators. The results show that all of these indicators have a statistically significant effect on the educational gradient of fertility intentions, albeit in different ways. On the one hand, the share of women with tertiary education among all women participating in the labour market and the gender ratio in labour force participation (as well as its trend component) have negative effects on the effect size; i.e. they reduce the educational differences in fertility intentions (models 4 and 5, respectively). On the other hand, the trend component of female part-time employment and the percentage of women in vulnerable employment have positive effects on the effect sizes; i.e. they increase the educational differences in fertility intentions (models 3 and 6, respectively). If, however, country clusters dummies are included in the models, the effects of these labour market macro indicators decrease in magnitude and even lose their statistical significance (models 7 to 10), which implies that these labour market features explain a significant portion of the cross-cluster variance in the effect size of education on birth intentions, as our third research hypothesis suggested. The indicator of inter-study variance, which shows how much the effect sizes vary between the single studies, can be interpreted as a measure of model fit: the smaller it is, the better the selected control variables explain the variance between single studies. According to this interpretation, model 2, which includes the set of country cluster dummies, provides the best fit for the data. This finding suggests that the diversity across countries is not explained by labour market indicators alone.

\section{Concluding remarks}

This investigation sought to validate empirical evidence of a positive educationfertility intentions link in Europe (Testa 2014). We conducted a meta-analysis of research published between 1990 and 2011 on fertility intentions using 86 study lines for 13 European countries. The application of a meta-analytical approach to the study of fertility intentions is entirely new in the literature. Given that reproductive decisions are sequential and individuals' life courses are gendered, we focused on the first and second birth intentions of women and men separately. In addition, we controlled for possible confounders (such as age, partnership status, and employment status) by selecting only studies that provided regression estimates. Finally, we covered several geographical regions and grouped studies into clusters of countries that reflect different economic, institutional, and policy contexts.

The meta-analysis revealed a positive educational gradient of both first and second birth intentions among both men and women. Thus, our findings lend support to previous cross-country empirical research that found a positive correlation between education and fertility intentions in Europe (Testa 2014). As 
predicted, the slope of the gradient was shown to be steeper for men than for women; and to be more pronounced for second than for first birth intentions, especially among women (second research hypotheses). The relationship between educational attainment and birth intentions was also found to be positive among women and men at the start of childbearing; i.e. among those who were forming their first birth intentions (first research hypothesis). For this group, the correlation was found to be stronger among men than among women, as the finding that the effect size is larger in the men's than in the women's forest plot suggests.

One potential explanation for these gender differences is that the income effect is more important than the substitution effect among men than among women. It is possible that men have higher intended fertility than women across parities because men tend to have more financial resources and to face lower economic costs when having children (Berrignton 2004). The parity differences can be read in light of the persistence of the two-child family norm, which is, surprisingly, just as common among the most emancipated social group of highly educated women (Testa 2014) and men as it is among other educational groups. We speculate that this outcome is attributable to the unique reasons that drive highly educated people to have a first and a second child, which are, respectively, the desire to become a parent and the desire to provide the first child with a companion. Additionally, parity differences can be explained by evidence showing that highly educated women tend to have their children over a shorter time period because they start later, and thus have less time to reproduce before reaching the end of their fertile period (time squeeze) (Kreyenfeld 2002). Hence, if highly educated women are at parity one, they will be more likely than their less educated counterparts to be observed while planning their second birth. Another possible explanation is related to the selection stemming from a parity-specific analysis; i.e. there are unobservable variables that could be correlated with the probability of having a child in parity $\mathrm{n}$ (in this case, zero), as well as with the probability of intending to have a child of the next order, $n+1$ (in this case, one). Thus, the women and men who are at parity one are also more likely to intend to have a second child (self-selection) (Kreyenfeld 2002).

The meta-data could not tell us whether this positive correlation emerged only recently as a result of the implementation of policies designed to facilitate workfamily balance, or had been present in earlier decades. We were unable to answer this question because in the meta-sample collection, there were too few studies for the same countries across time, and we could not go back earlier than 1990. The finding in the meta-regression that the midpoint of the data interval used in the study line lacked statistical significance suggests that there was no temporal change in the educational gradient of birth intentions in the years 1990-2011.

In support of the third research hypothesis, we found that the educational gradient of birth intentions was positively correlated with the trend in the share of women in part-time employment: in contexts in which women increasingly opted for part-time employment, the educational differences in birth intentions were larger. Women often choose to work part-time to facilitate the combining of work and family life. This result therefore suggests that more educated women could be encouraged to 
have larger families by an increase in the availability of part-time work, which would make it easier for them to have both a career and a family with (more) children. Moreover, the educational gradient of birth intentions was found to be positively correlated with the share of women in vulnerable employment arrangements. The most plausible explanation for this finding is that the largest educational differences were driven by the lower fertility intentions of the less educated women who experienced more labour market vulnerability.

In line with the third research hypothesis, we found that gender equality in labour force participation and the share of highly qualified women in employment were reducing the educational gradient of birth intentions. This suggests that labour markets supportive of working mothers can perhaps ease the opportunity costs of childbearing for lower educated women, and can therefore encourage them to develop fertility plans that are more similar to those of their more educated counterparts. Alternatively, labour markets supportive of working higher educated mothers might allow them to be more focused on their careers, and in turn reduce their fertility intentions for additional children, hence making them more similar to the intentions of their lower educated counterparts.

This study has several caveats, which may provide direction for future research. First, the criteria of cross-country comparability and quality used in the selection of the meta-sample led us to sharply reduce our initial collection of papers: the sample of 161 papers was narrowed to just 23 papers, and almost none of these remaining papers examined third or higher order birth intentions. This suggests that although the number of studies on reproductive intentions has increased considerably in recent decades, this research topic remains under-investigated. Second, differences in the educational gradient (size effects) cannot be clearly traced back to elevated intentions among the highly educated, and the source of the change in the effect sizes in the educational gradient remains unknown. This suggests that there is an opportunity to complement this quantitative literature review with statistical analyses based on cross-country comparative datasets; and to include other dimensions such as enrolment in education and field of education, both of which are very relevant for reproductive choices (Blossfeld and Huinink 1991; Hoem et al. 2006; Tesching 2012). Third, because only a few countries have study lines available for several years, it was not possible to conduct deep investigations into the temporal trends of national patterns and the effects of changes in institutional support for families. Furthermore, the distribution of study lines across parities was very unbalanced, with some countries providing study lines for all parity statuses, and others providing study lines for just one parity status (either zero or one child). Gender distribution was also unbalanced, with some countries providing study lines for both men and women, and other countries offering study lines for women only.

The limited availability of study lines by country forced us to cluster together countries with different welfare regimes, institutional contexts, and labour markets, like the UK, Norway, and Finland. While we acknowledge this limitation, we can reasonably assume that the ranking of the countries clusters in the meta-analytic 
regression - with the effect sizes being the biggest in the Southern European countries and the smallest in the Northern European countries - would not have been substantially different if the UK had been removed from the Northern European cluster. On the other hand, in the regression models 2 to 6 , which included labour market indicators but not cluster dummies, the assumption of a homogeneous cluster of Northern Europe (i.e. the UK, Finland, and Norway) was implicitly released.

Finally, the studies collected in the meta-analysis might have been subject to selection bias. Since highly educated women (and men) are more likely to postpone the start of childbearing than their less educated counterparts, they are also more likely than less educated women and men to be observed at a stage of their reproductive career when they have yet to realise their fertility plans. Thus, the first and second birth intentions of the highly educated would be artificially inflated by the inclusion of children in the future component of family size. This issue, as well as the possibility that there are unobserved characteristics ${ }^{8}$ that could influence both education and reproductive decisions, cannot be tackled with the meta-data at hand, which are restricted by the design of the analysis adopted in the selected study lines (as almost none of them modelled explicitly selection bias and endogeneity due to unobserved heterogeneity). We hope that new longitudinal studies will shed light on this critical topic by investigating the reproductive decision-making processes of highly and less educated women and men over a long time span.

In light of the existing body of literature, this study is the first comparative metaanalysis of the interplay between educational attainment and fertility intentions. It is, however, limited by the number of published comparable studies that could be retained in the final meta-sample, which is indeed very small (i.e. only 23 papers out of the 161 initially selected papers). This severe restriction in the literature suitable for such analyses calls for further research, and suggests that there is a need to adopt standard measures of fertility intentions that would enhance comparability over time and across countries; as well as to enlarge the sample sizes in fertility surveys, as doing so would allow for a deeper investigation of men's and women's birth order intentions beyond parity two. Given the steadily growing body of empirical analysis in the realm of fertility intentions, future meta-analytical studies might have a better starting position as a result of the guidelines this work is able to provide.

\section{Acknowledgments}

This work was supported by the Austrian Science Fund (FWF) under the Grant G22-V318, Elise Richter project "Reproductive decision-making and human capital" (more details are available at http://recap.wu.ac.at/). We are grateful to

\footnotetext{
8 In a recent study, the variation in the educational gradient in second births was found to be associated with a positive link between fertility and economic conditions, as well as social services for the highly educated women and men (Wood et al. 2017).
} 
Anna Matysiak and Daniela Bellani for their numerous and valuable comments during the development of this research. An earlier version of this paper was presented at the European Population Conference 2014. We would like to thank the participants for their useful and generous remarks.

\section{References $^{10}$}

Adsera, A. 2011. The interplay of employment uncertainty and education in explaining second births in Europe. Demographic Research 25(16): 513-544.

Ajzen, I. 1991. The theory of planned behavior. Organizational Behavior and Human Decision Processes 50(2): 179-211.

Ajzen, I. and J. Klobas 2013. Fertility intentions: an approach based on the theory of planned behaviour. Demographic Research 29(8): 203-232.

Amato, P. and B. Keith 1991. Parental divorce and adult well-being: A meta-analysis, Journal of Marriage and the Family, 53(1): 43-58.

Andersson, G., M. Rønsen, M. L. Knudsen, T. Lappegård, G. Neyer, K. Skrede, K. Teschner and A. Vikat 2009. Cohort fertility patterns in the Nordic countries. Demographic Research 20(14): 313-352.

Bachrach, C. A. and S. P. Morgan 2011. Further reflections on the theory of planned behaviour and fertility research. Vienna Yearbook of Population Research 9: 71-74.

Balbo, N. and M. Mills 2011. The effects of social capital and social pressure on the intention to have a second or third child in France, Germany, and Bulgaria, 2004-05. Population Studies 65(3): 335-351.

Bankole, A. 1995. Desired fertility and fertility behaviour among the Yoruba of Nigeria: A study of couple preferences and subsequent fertility. Population Studies 49(2): 317-328.

Baranowska-Rataj, A. and A. Matysiak 2014. The causal effect of the number of children on female employment - do European institutional and gender conditions matter? Warsaw, Poland: Institute of Statistics and Demography. Warsaw School of Economics Working Paper No. 39.

Becker, G. S. 1960. An economic analysis of fertility. Demographic and Economic change in developed countries. Princeton: Universities-National Bureau of Economic Research (NBER).

Becker, G. 1991. A treatise on the family. London: Harvard University Press.

Becker, G. and H. G. Lewis 1973. On the interaction between the quantity and the quality of children. The Journal of Political Economy 81(2): S279-S288.

Bellani, D. and G. Esping-Andersen 2013. Education, employment and fertility. In EspingAndersen, G. (ed.) The fertility gap in Europe: singularities of the Spanish case. Barcelona: "la Caixa" Welfare Projects: 82-101.

Berninger, I., B. Weiß and M. Wagner 2011. on the links between employment, partnership quality, and the intention to have a first child: the case of West Germany. Demographic Research 24(24): 579-610.*

10 All studies marked with an asterisk have been considered for our meta-analysis. 
Berrington, A. 2004. Perpetual postponers? Women's, men's and couple's fertility intentions and subsequent fertility behaviour. Population trends 117: 9-19.*

Billari, F. C., D. Philipov and M. R. Testa 2009. Attitudes, norms and perceived behavioural control: Explaining fertility intentions in Bulgaria. European Journal of Population/Revue européenne de Démographie 25(4): 439-465.

Billari, F. C. and D. Philipov 2004. Education and transition to motherhood: a comparative analysis of Western Europe. European Demographic Research Papers No. 3. Vienna Institute of Demography.

Björklund, A. 2006. Does family policy affect fertility? Journal of Population Economics 19: $3-24$.

Blettner, Maria, Willi Sauerbrei, Brigitte Schlehofer, Thomas Scheuchenpflug, and Christine Friedenreich 1999. Traditional reviews, meta-analyses and pooled analyses in epidemiology, International Journal of Epidemiology 28(1): 1-9.

Blossfeld, H.-P. and J. Huinink 1991. Human capital investments or norms of role transition? How women's schooling and career affect the process of family formation. American Journal of Sociology 97: 143-168.

Borenstein, M., L. Hedges, J. Higgins and H. Rothstein 2010. A basic introduction to fixedeffect and random-effect models for meta-analysis, Research Synthesis Methods 1/2010: 97-111.

Bühler, C. and E. Fratczak 2005. Social capital and fertility intentions: the case of Poland. Working Paper No. 2004-012.*

Bühler, C. and E. Fratczak 2007. Learning from others and receiving support: The impact of personal networks on fertility intentions in Poland. European Societies 9(3): 359-382.

Castro-Martín, T. and T. Martín-García 2013. The fertility gap in Spain: late parenthood, few children and unfulfilled reproductive desires. In: Esping-Andersen, G. (ed.) The Fertility Gap in Europe: Singularities of the Spanish Case. Barcelona: "la Caixa" Welfare Projects. 45-81.

Caltabiano, M., M. Castiglioni and A. Rosina 2009. Lowest-low fertility: signs of a recovery in Italy? Demographic Research 21(23): 681-718.

Cavalli, L. 2012. Fertility Intentions of Employed Mothers in Italy: Does the Choice of Public versus Private Sector Matter? Working Paper No. 27, University of Verona.*

Cook, T. D., L. C. Leviton 1980. Reviewing the literature: a comparison of traditional methods with meta-analysis. Journal of Personality 48: 449-472.

De Wachter, D. and K. Neels 2011. Educational differentials in fertility intentions and outcomes: family formation in Flanders in the early 1990s. Vienna Yearbook of Population Research 9: 227-258.

Dharmalingam, A. and S. P. Morgan 2004. Pervasive Muslim-Hindu Fertility Differences in India. Demography 41(3): 529-545.

Dibaba, Y. 2009. Factors influencing women's intention to limit child bearing in Oromia, Ethiopia. Ethiopian Journal of Health Development 23(1): 28-33.

Dommaraju, P. and V. Agadjanian 2009. India's North-South divide and theories of fertility change. Journal of Population Research 26(3): 249-272. 
Dommermuth, L., J. Klobas and T. Lappegård 2011. Now or later? The theory of planned behavior and timing of fertility intentions. Advances in Life Course Research 16(1): 42-53.*

Duvander, A. Z., T. Lappegård and G. Andersson 2010. Family policy and fertility: fathers' and mothers' use of parental leave and continued childbearing in Norway and Sweden. Journal of European Social Policy 20(1): 45-57.

Edmonston, B., S. M. Lee and Z. Wu 2010. Fertility intentions in Canada: change or no change? Canadian Studies in Population 37(3-4): 297-337.

Esping-Andersen, G. 1999. Social foundations of postindustrial economies. New York: Oxford University Press.

Esping-Andersen, G. (ed.) 2013. The fertility gap in Europe: singularities of the Spanish case. Barcelona: "la Caixa" Welfare Projects.

Fiori, F. 2011. Do childcare arrangements make the difference? A multilevel approach to the intention of having a second child in Italy. Population, Space and Place 17(5): 579-596.*

Hanappi, D., VA. Ryser and L. Bernardi 2014. Coping strategies under uncertain, precarious employment conditions in Switzerland, Families and Societies, Working Paper Series 12.*

Hassen, M. A. 2013. Assessment of Sexual Behavior, Unmet Reproductive Health Needs and Fertility Intention of People Living with HIV/AIDS, Jimma, South West of Ethiopia. Global Journal of Medical Research 13(2): 24-33.

Hayford, S. R. 2009. The evolution of fertility expectations over the life course. Demography 46(4): 765-783.

Hayford, S. R. and V. Agadjanian 2011. Uncertain future, non-numeric preferences, and the fertility transition: A case study of rural Mozambique, African Population Studies 25(2): 419-439.

Hayford, S. R. and S. P. Morgan 2008. Religiosity and fertility in the United States: The role of fertility intentions. Social Forces 86(3): 1163-1188.

Heard, I., R. Sitta and F. Lert 2007. Reproductive choice in men and women living with HIV: evidence from a large representative sample of outpatients attending French hospitals (ANRS-EN12-VESPA Study). Aids 21: S77-S82.*

Hedges, L. V. and I. Olkin 1985. Statistical methods for meta-analysis. Orlando, FL: Academic.*

Heiland, F., A. Prskawetz and W. C. Sanderson 2008. Are individuals' desired family sizes stable? Evidence from West German panel data. European Journal of Population/Revue Européenne de Démographie 24(2): 129-156.*

Hiekel, N. and T. Castro-Martín 2014. Grasping the diversity of cohabitation: fertility intentions among cohabiters across Europe. Journal of Marriage and Family 76(3), 489505.

Hoem, J. M., Neyer and G. Andersson 2006. Education and childlessness: the relationship between educational field, educational level, and childlessness among Swedish women born in 1955-59. Demographic Research 14(15): 331-380.

Iacovou, M. and Tavares L. P. 2011. Yearning, learning and conceding: reasons men and women change their childbearing intentions. Population and Development Review 37(1): 89-123. 
Johnson-Hanks, J. A., C. A. Bachrach, S. P. Morgan, H.-P. Kohler 2011. Understanding family change and variation: toward a theory of conjunctural action. Springer.

Kocourková, J. 2002. Leave arrangements and childcare services in Central Europe: policies and practices before and after the transition. Community, Work $\mathcal{E}$ Family 5(3): 301-318.

Kharkova, T. L. and E. M. Andreev 2000. Did the economic crisis cause the fertility decline in Russia: Evidence from the 1994 Microcensus. European Journal of Population/Revue Européenne de Démographie 16(3): 211-233.

Kipp, W., J. Heys, G. S. Jhangri, A. Alibhai and T. Rubaale 2011. Impact of antiretroviral therapy on fertility desires among HIV-infected persons in rural Uganda. Reproductive Health 8(1): 27.

Kohler, H-P., F. C. Billari and J. A. Ortega 2002. The emergence of lowest-low fertility in Europe during the 1990s. Population and Development Review 28(4): 641-680.

Kohler, HP., J. L. Rodgers 2003. Education, fertility, and heritability: explaining a paradox. In: Sobotka, T. 2009. Sub-replacement fertility intentions in Austria. European Journal of Population 25(4): 387-412.

Korpi, W. 2000. Faces of inequality: gender, class and patterns of inequalities in different types of welfare states. Luxembourg Income Study. Working Paper No. 224.

König, S. 2011. Higher order births in Germany and Hungary, MZES Working Paper, 146, Mannheim.*

Kravdal, Ø. and R. R. Rindfuss 2008. Changing relationship between education and fertility: a study of women and men born 1940 to 1964. American Sociological Review 73(5): 854-873.

Kreyenfeld, M. 2002. Time-squeeze, partner effect or self-selection? An investigation into the positive effect of women's education on second birth risks in West Germany. Demographic Research 7(2): 15-48.

Lambert, S. M., P. Masson and H. Fisch 2006. The male biological clock. World Journal of Urology 24(6): 611-617.

Lappegård, T. 2012. Gender ideology and fertility intentions across Europe. In Population Association of America (p.1-4).

Lappegård, T., M. Ronsen and K. Skrede 2011. Fatherhood and fertility. Fathering: a Journal of Theory, Research and Practice about Men as Fathers 9(1): 103-120.

Leibenstein, H. 1974. An interpretation of the economic theory of fertility: Promising path or blind alley? Journal of Economic Literature 12(2): 457-479.

Lesthaeghe, R. and J. Surkyn 1988. Cultural dynamics and economic theories of fertility change. Population and Development Review 14(1): 1-45.

Lesthaeghe, R. 2010. The unfolding story of the second demographic transition. Michigan: Population Studies Center (Research Report No. 10-696).

Liefbroer A. C. 2009. Changes in family size intentions across young adulthood: a life course perspective. European Journal of Population 25(4): 363-386.

Liefbroer A. C. and M. Corijn 1999. Who, what, where and when? Specifying the impact of educational attainment and labour force participation on family formation. European Journal of Population 15(1): 45-75.

Lipsey, Mark W. and David B. Wilson 2001. Practical meta-analysis. London and New Delhi: Sage. 
Mahmood, N. 1992. The desire for additional children among Pakistani women: The determinants. The Pakistan Development Review 1-30.

Marcellin, F., C. Protopopescu, C. Abé, S. Boyer, J. Blanche, P. Ongolo-Zogo and the EVAL Study Group 2010. Desire for a child among HIV-infected women receiving antiretroviral therapy in Cameroon: results from the national survey EVAL (ANRS 12-116). Aids Care 22(4): 441-451.

Martin-Garcia, T. 2008. 'Bringing men back in': a re-examination of the impact of type of education and educational enrolment on first births in Spain. European Sociological Review 25(2): 199-213.

Morgan, S. P. and M. G. Taylor 2006. Low fertility at the turn of the twenty-first century. Annual Review of Sociology 1(32): 375-399.

Matysiak, A. and D. Vignoli 2008. Fertility and women's employment - a meta-analysis. European Journal of Population Revue Européenne de Démographie 24(4): 363-384.

Mencarini, L., S. Salvini, L. Secondi and D. Vignoli 2010. Having children in Italy: from intentions to realizations. Working Paper, Universita di Torino: Collegio Carlo Alberto, $1-8$.*

Miettinen, A., S. Basten and A. Rotkirch 2011. Gender equality and fertility intentions revisited: evidence from Finland. Demographic Research 24(20): 469-496.*

Miller, W. B. 2011. Fertility desires and intentions: construct differences and the modeling of fertility outcomes. Presented at the conference From Intentions to Behaviour: Reproductive Decision-making in a Macro-micro Perspective organized by the Vienna Institute of Demography and the international project REPRO and taking place in Vienna, Austria on December 2-3, 2010.

Mills, M., L. Mencarini, M. L. Tanturri and K. Begall 2008. Gender equity and fertility intentions in Italy and the Netherlands. Demographic Research 18(1): 1-26.*

McQuillan, J., A. L. Greil, K. M. Shreffler and A. V. Bedrous 2014. The importance of motherhood and fertility intentions among U.S. women. Sociological Perspectives 6: $1-16$.

Muresan, C. and J. M. Hoem 2010. The negative educational gradients in Romanian fertility. Demographic Research 22(4): 95-114.

Musick, K., P. England, S. Edgington and N. Kangas 2009. Education differences in intended and unintended fertility. Social Forces 88(2): 543-572.

Namboodiri 1983. Sequential fertility decision making and the life course. In Determinants of fertility in developing countries. Volume 2. Fertility regulation and institutional influences, eds R. A. Bulatao and R. D. Lee, 444-472. New York: Academic Press.

Neyer, G. 2013. Welfare states, family policies, and fertility in Europe. In The demography of Europe (pp. 29-53). Springer Netherlands.

Ní Bhrolcháin, M. and É. Beaujouan 2011. Uncertainty in fertility intentions in Britain, 1979-2007. Vienna Yearbook of Population Research 9: 99-129.*

Ní Bhrolcháin, M. and É. Beaujouan 2012. Fertility postponement is largely due to rising educational enrolment. Population Studies 66(3): 311-327.

Nóbrega, A. A., F. A. Oliveira, M. T. Galvão, R. S. Mota, R. M. Barbosa, I. Dourado, ... and L. R. Kerr-Pontes 2007. Desire for a child among women living with HIV/AIDS in Northeast Brazil. AIDS Patient Care and STDs 21(4): 261-267. 
Oluwaseyi, A. T. 2013. Fertility intention and contraceptive use among males in Nigeria. Doctoral dissertation.

Oppenheimer, V. K. 1988. A Theory of Marriage Timing. The American Journal of Sociology, 94: 563-591.

Pailhé, A. 2009. Work-family balance and childbearing intentions in France, Germany and the Russian Federation. In How Generations and gender shape demographic change. Towards policies based on better knowledge. Conference Proceedings. Geneva 14-16 May 2008. United Nations Economic Commission for Europe (UNECE): 57-82.*

Paiva, V., N. Santos, I. França-Junior, E. Filipe, J. R. Ayres and A. Segurado 2007. Desire to have children: gender and reproductive rights of men and women living with HIV: a challenge to health care in Brazil. AIDS Patient Care and STDs 21(4): 268-277.

Park, S. M. 2012. Social networks and second-childbirth intentions of Korean married women. Journal of Reproductive and Infant Psychology 30(4): 398-412.

Philipov, D. 2011. Theories of fertility intentions: a demographer's perspective. Vienna Yearbook for Population Research 9: 37-45.

Philipov, D. 2002. Fertility in times of discontinuous societal change: the case of Central and Eastern Europe. Working Paper WP, 24.*

Philipov, D., Z. Spéder and F. C. Billari 2005. Now or later fertility intentions in Bulgaria and Hungary and the impact of anomie and social capital, Working Paper 82005, Vienna Institute of Demography.*

Philipov, D., Z. Spéder and F. C. Billari 2006. Soon, later, or ever? The impact of anomie and social capital on fertility intentions in Bulgaria (2002) and Hungary (2001).Population Studies 60(3): 289-308.*

Rindfuss, R. R., S. P. Morgan and K. Outt 1996. Education and the changing pattern of American fertility: 1963-1989. Demography 33(3): 277-290.

Rinesi, F., A. Pinnelli, S. Prati, C. Castagnaro and C. Iaccarino 2011. The transition to second child in Italy expectations and realization. Population 66(2): 391-405.*

Ruokolainen, A. and I. L. Notkola 2002. Familial, situational and attitudinal determinants of third-birth intentions and their uncertainty. Yearbook of Population Research in Finland 38: 179-206.

Schmitt, C. 2012. Labour market integration, occupational uncertainty, and fertility choices in Germany and the UK. Demographic Research 26(12): 253-292.*

Sobotka, T. 2009. Sub-replacement fertility intentions in Austria. European Journal of Population/Revue Européenne de Démographie 25(4): 387-412.

Sterne, J. A. C. (ed.) 2009. Meta-analysis in Stata: an updated collection from the Stata Journal. Stata Press.*

Sweet, J. A. and R. R. Rindfuss 1983. Those ubiquitous fertility trends: United States, 1945-1979. Social Biology 30(2): 127-139.

Tamene, W. and M. Fantahun 2007. Fertility desire and family-planning demand among HIVpositive women and men undergoing antiretroviral treatment in Addis Ababa, Ethiopia. African Journal of AIDS research 6(3): 223-227.

Tanskanen, A. and A. Rotkirch 2014. The impact of grandparental investment on mothers' fertility intentions in four European countries. Demographic Research 31(1): 1-26. 
Tesching, K. 2012. Education and Fertility. Dynamic Interrelations Between Women's Educational Level, Educational Field and Fertility in Sweden. Doctoral Thesis in Sociological Demography. Stockholm University. Demographic Unit. Dissertation Series No. 6.

Tesfaye, L., M. Admassu, A. Getachew and H. R. Sharma 2012. Fertility desires and family planning demand among HIV-positive clients in follow-up care at antiretroviral treatment unit in Gondar University hospital, Ethiopia. Vulnerable Children and Youth Studies 7(1): 20-35.*

Testa, M. R. and L. Grilli 2006. The influence of childbearing regional contexts on ideal family size in Europe. Population 61(1): 99-127.

Testa, M. R. 2010. Child-number and child-timing intentions in a micro-macro European framework. European Demographic Research Paper, 4. Vienna Institute of Demography of the Austrian Academy of Sciences.*

Testa, M. R. 2012a. Family sizes in Europe: evidence from the 2011 Eurobarometer survey. European Demographic Research Papers, 2, Vienna Institute of Demography of the Austrian Academy of Sciences.

Testa, M. R. 2012b. Women's fertility intentions and level of education: why are they positively correlated in Europe. European Demographic Research Papers, 3. Vienna Institute of Demography of the Austrian Academy of Sciences.

Testa, M. R. 2012c. Couple disagreement about short-term fertility desires in Austria: effects on intentions and contraceptive behaviour. Demographic Research 26(3): 63-98.*

Thévenon, O. 2008. Family policies in Europe: available databases and initial comparisons. Vienna Yearbook of Population Research 6: 165-177.

Thomson, R. and C. Lee 2011. Sooner or later? Young Australian men's perspectives on timing of parenthood. Journal of Health Psychology 16(5): 807-818.

Van de Kaa, D. 2002. The idea of a second demographic transition in industrialized countries. Paper presented at the Sixth Welfare Policy Seminar of the National Institute of Population and Social Security, Tokyo, Japan, January 29.

Wachter, K. W. and R. A. Bulatao (eds) 2003. Offspring: human fertility behavior in biodemographic perspective. Washington: National Academic Press: 46-90.

Waldforf, Brigitte and Byun Pillsung 2005. Meta-analysis of the impact of age structure on fertility. Journal of Population Economics 18: 15-40.

Wampler, K. 1982. Bringing the review of literature into the age of quantification: metaanalysis as a strategy for integrating research findings in family studies. Journal of Marriage and the Family 44: 1009-1023.

Wu, Z. and H. Wang 1998. Third birth intentions and uncertainty in Canada. Biodemography and Social Biology 45(1-2): 96-112.

Yeatman, S., C. Sennott and S. Culpepper 2013. Young women's dynamic family size preferences in the context of transitioning fertility. Demography 50(5): 1715-1737.

Yu, P. 2006. Higher education, the bane of fertility? An investigation with the HILDA Survey. Working Paper, Australian National University. 